Hu et al./p1

\title{
Perturbed ovarian and uterine glucocorticoid receptor signaling accompanies the balanced regulation of mitochondrial function and NFKB-mediated inflammation under conditions of hyperandrogenism and insulin resistance
}

Min $\mathrm{Hu}^{1,2}$, Yuehui Zhang ${ }^{2,3}$, Xiaozhu Guo ${ }^{3}$, Wenyan $\mathrm{Jia}^{3}$, Guoqi $\mathrm{Liu}^{3}$, Jiao Zhang ${ }^{4}$, Peng Cui ${ }^{2,5}$, Juan $\mathrm{Li}^{1,2}$, Wei $\mathrm{Li}^{3}$, Xiaoke $\mathrm{Wu}^{3}$, Hongxia $\mathrm{Ma}^{1}$, Mats Brännström ${ }^{6}$, Linus R Shao ${ }^{2, \star}$ and Håkan Billig ${ }^{2}$

${ }^{1}$ Department of Traditional Chinese Medicine, The First Affiliated Hospital of Guangzhou Medical University, 510120 Guangzhou, China

2 Department of Physiology/Endocrinology, Institute of Neuroscience and Physiology, The Sahlgrenska Academy, University of Gothenburg, 40530 Gothenburg, Sweden

${ }^{3}$ Department of Obstetrics and Gynecology, Key Laboratory and Unit of Infertility in Chinese Medicine, First Affiliated Hospital, Heilongjiang University of Chinese Medicine, 150040 Harbin, China

${ }^{4}$ Department of Acupuncture and Moxibustion, Second Affiliated Hospital, Heilongjiang University of Chinese Medicine, 150040 Harbin, China

${ }^{5}$ Department of Gynecology, Shuguang Hospital affiliated to Shanghai University of Traditional Chinese Medicine, 201203 Shanghai, China

${ }^{6}$ Department of Obstetrics and Gynecology, Sahlgrenska University Hospital, Sahlgrenska Academy, University of Gothenburg, 41345 Gothenburg, Sweden

* Corresponding author: Linus R Shao, M.D., Ph.D.; Tel: +46 31-7863408; Fax: +46 31-7863512; Email: linus.r.shao@fysiologi.gu.se

Running title: Ovarian and uterine GR signaling under PCOS conditions 
Hu et al./p2

\section{Abstract}

Hyperandrogenism and insulin resistance are co-pathologies of polycystic ovary syndrome (PCOS). Recent evidence has suggested that elevated local cortisol levels are associated with ovarian and endometrial insulin resistance in hyperandrogenic PCOS patients, but the molecular mechanisms underlying these clinical findings remain unclear. We and others have used chronic treatment with human chorionic gonadotropin (hCG) and insulin to create an in vivo rodent model for the onset and development of PCOS-like phenotypes. Here, we aimed to determine whether the molecular mechanisms of glucocorticoid receptor (GR) signaling, mitochondrial function, and local inflammation in the ovary and uterus are intrinsically different in PCOS-like rats compared to controls. In both the ovary and the uterus, decreased expression of two GR protein isoforms was concurrent with increased expression of Fkbp51 but not Fkbp52 mRNA in PCOS-like rats compared to controls. However, PCOS-like rats exhibited an opposite regulation of Hsd11b1 or Hsd11b2 mRNAs in the two tissues. Further, the expression of several oxidative phosphorylation-related protein components was decreased in the PCOS-like ovary and uterus, but surprisingly the expression of many genes involved in mitochondrial function and homeostasis was increased in the same tissues and animals. Additionally, PCOS-like rats showed the increased expression of ovarian and uterine NFKB signaling proteins and Tnfaip3 mRNA. In PCOS-like rats, while similar decreased expression of $/ / 1 b, \| / 6$, and Mmp2 mRNAs was seen in the ovary and uterus, the opposite regulation of Tnfa, Ccl2, Cc/5, and Mmp3 mRNA expression was observed in the two tissues. Both ovaries and uteri from PCOS-like animals showed increased collagen deposition compared to controls. Collectively, our observations suggest that hyperandrogenism and insulin resistance disrupt ovarian and uterine GR activation and trigger compensatory or adaptive effects for mitochondrial homeostasis, allowing tissue-level maintenance of mitochondrial function in order to limit ovarian and uterine dysfunction. Our study also suggests that hyperandrogenism and insulin resistance-induced activation of NFKB signaling resulting in aberrant regulation of inflammation-related gene expression might be tissue specific in female reproductive tissues.

Key words: glucocorticoid receptor; 11HSD; mitochondria; NFkB; inflammation; ovary; uterus; polycystic ovary syndrome 
Hu et al./p3

\section{Introduction}

Worldwide, $4 \%-21 \%$ of all adolescent and reproductive-aged women are diagnosed with polycystic ovary syndrome (PCOS), which is a complex, heterogeneous hormone-imbalance disorder [1]. Extensive evidence from clinical studies suggests that PCOS patients commonly have impaired ovarian folliculogenesis and chronic anovulation, and their endometrium tends to remain in a proliferative state [2], which likely results in disrupted processes of uterine decidualization and embryo implantation [ $\underline{3}, 4]$. These defects cause approximately $75 \%$ of PCOS patients to suffer from anovulation infertility [5], and approximately $50 \%$ of PCOS patients experience recurrent pregnancy loss [6]. Although hyperandrogenism and insulin resistance either alone or in combination are recognized as the central manifestations in PCOS patients [7-9], the precise pathophysiological mechanisms of this syndrome that result in disrupted ovarian and uterine function are far from completely understood.

Glucocorticoid receptor (GR) is a ligand-dependent transcription-regulating protein belonging to the steroid receptors in the superfamily of nuclear receptors [10]. Among its other actions [10], GR plays a critical role in female reproduction [11]. For instance, GR is highly expressed in the mammalian ovary and uterus [12, 13], and genetic models have demonstrated a physiological role for GR as a required factor for embryo implantation and decidualization [14]. The GRa and GRß isoforms are encoded in both humans and rodents, and there is compelling evidence that cellular GRa, but not GR $\beta$, is principally activated by binding of ligands such as cortisol in humans and corticosterone in rodents $[\underline{10}$, 11]. Human studies have previously reported that the use of dexamethasone, an exogenous glucocorticoid drug, induces abnormal glucose homeostasis and impairs peripheral insulin sensitivity $[15,16]$. Similarly, treatment with dexamethasone also results in peripheral and tissue-specific insulin resistance and decreased ovarian $17 \beta$-estradiol production in different animal models [17-19]. While systemic and tissue-specific insulin resistance is often seen in PCOS patients [으, $\underline{9}$ and PCOS-like animal models [20-22], intracellular GR signaling might be maintained and continue to play a critical role in PCOS. Supporting this notion are clinical studies demonstrating a positive association between elevated local cortisol levels and ovarian and endometrial insulin resistance in PCOS patients [23, 24]. In addition to insulin resistance, hyperandrogenism, particularly of ovarian origin, is the cornerstone of PCOS pathophysiology [7], and we and others have previously reported the aberrant expression of ovarian and endometrial androgen receptor (AR) in PCOS patients compared to non-PCOS controls 
[25-27]. Because there is high similarity in the DNA-binding domains, the ligand-binding domains, and the hormone response elements between GR and AR [28], it would be most informative to study the molecular mechanisms of ovarian and uterine GR signaling under the conditions of hyperandrogenism and/or insulin resistance in vivo.

It is notable that some [29, $\underline{30}$, but not all, clinical studies have shown that elevated circulating cortisol levels and its metabolism are associated with PCOS [31]. However, the circulating and tissue levels of glucocorticoids do not always reflect each other in PCOS patients. This is partly due to the fact that increased expression and activity of intracellular $11 \beta$-hydroxysteroid dehydrogenase (11ßHSD) 1, the pre-receptor regulator of glucocorticoids, determines the local cortisol concentrations in a tissue-specific manner [32], as reported in adipose tissues in PCOS patients [33]. 11ßHSD, which is a member of the short-chain dehydrogenase/reductase superfamily, is important for intracellular glucocorticoid metabolism and action in the target tissues/cells [34]. It is expressed as two isoforms, 11ßHSD1 (Hsd11b1) and 11ßHSD2 (Hsd11b2), and they are co-expressed in most tissues, including the ovary and uterus in humans and rodents $[11, \underline{34}$. In humans, while $11 \beta H S D 1$ functions mainly as a reductase converting inactive cortisone to active cortisol, 11ßHSD2 acts exclusively as an oxidase converting cortisol to cortisone [34]. In rodents, corticosterone is a main active glucocorticoid, whereas 11-dehydrocorticosterone is an inactive glucocorticoid [34]. The functional roles of 11ßHSD1 and $11 \beta \mathrm{HSD} 2$ in rodents are similar to those in humans. These findings suggest that the distinct expression patterns and enzymatic activities of $11 \beta \mathrm{HSD}$ isoforms might change in opposite directions in order to regulate the local concentration of cortisol/corticosterone in a particular tissue or cell type. In addition, the tissue-specific regulation of the 11ßHSD isoforms in response to a variety of pathophysiological stimuli has been investigated as a potential method for activating or suppressing the GR signaling pathway $[32, \underline{34}$. However, the causality of $11 \beta \mathrm{HSD}$ isoform dysregulation in the ovary and uterus under the conditions of hyperandrogenism and/or insulin resistance has never to our knowledge been experimentally determined in a PCOS-like animal model in vivo.

In addition to the nuclear translocation of GR from the cytoplasm [10, 11], GR can also be translocated to the mitochondria in many different cell types [35]. While mitochondria play a dynamic and multifaceted role in cell signaling and metabolism [36], several studies have demonstrated that mitochondrial GR contributes to the regulation of mitochondrial DNA gene transcriptional responses in a similar manner as it functions in the nucleus [35]. In fact, in vivo and in vitro studies have 
demonstrated that mitochondrial DNA (mtDNA) contains glucocorticoid response elements that can regulate mtDNA transcription in a ligand-dependent manner [37, 38]. In PCOS patients and PCOS-like animals, evidence is accumulating that hyperandrogenism and insulin resistance impair mitochondrial function in different tissues and cells in vivo [26, 39-45]. In addition, while glucocorticoid-mediated regulation of inflammatory and immune responses and female fertility is well studied [10, 11$]$, clinical studies also show a strong and frequent association between the development of PCOS and lowgrade chronic inflammation $[\underline{1}, \underline{3}, \underline{4}$. Although animal studies have provided us with a great deal of knowledge of the critical roles of human chorionic gonadotropin (hCG) and insulin treatment on ovarian and uterine insulin resistance $[20, \underline{46}]$ and on follicular cyst formation [22] - as well as several molecular mechanisms behind hyperandrogenism and insulin resistance $[2 \underline{20}, \underline{22}, \underline{46-50}]$ - the cellular significance of the connection between hyperandrogenism and insulin resistance and glucocorticoidGR signaling-mediated mitochondrial function and chronic inflammation in the ovary and uterus remains unclear.

In the present study, we comprehensively examined the distribution and alteration of GR signaling, mitochondrial function, and local inflammation in the rat ovary and uterus in response to chronic treatment with hCG and/or insulin, which mimics two of the main PCOS-related etiological factors. Our findings indicate that aberrant changes in GR expression and functionality may be involved in the ovarian and uterine pathological processes in PCOS.

\section{Materials and Methods}

\subsection{Ethics approval and animal care}

All animal experiments and animal care procedures were carried out according to the institutional guidelines for the care and use of animals in research. The studies were approved by the Animal Care and Use Committee of the Heilongjiang University of Chinese Medicine, China (HUCM 2015-0112). Adult female Sprague Dawley rats (70 days old) were obtained from the Laboratory Animal Centre of Harbin Medical University (Harbin, China) and were kept in groups with free access to food and water and a controlled temperature of $22 \pm 2{ }^{\circ} \mathrm{C}$ with a $12: 12 \mathrm{~h}$ light:dark cycle.

\subsection{Chemicals and reagents}

hCG was from NV Organon (Oss, Holland), and human recombinant insulin (Humulin NPH) was from Eli Lilly Pharmaceuticals (Giza, Egypt). Anti-mouse IgG horseradish peroxidase (HRP)conjugated goat (A2304), and anti-rabbit IgG HRP-conjugated goat (A0545) secondary antibodies 
144

145

146

147

148

149

150

151

152

153

154

155

156

157

158

159

160

161

162

163

164

165

166

167

168

169

170

171

172

173

were from Sigma-Aldrich (St. Louis, MO). The primary antibodies used for Western blot and immunohistochemical analyses in the present study, their dilutions, and their sources are listed in Table 1. The avidin-biotinylated-peroxidase complex detection system (ABC kit) was from Vector Laboratories Inc. (Burlingame, CA). A detailed list of primers is provided in Table 2. Unless otherwise specified, all reagents were purchased from Sigma-Aldrich (St Louis, MO, USA).

\subsection{Study design, estrous cycle analysis, and tissue collection}

The female Sprague Dawley rats $(n=88)$ used in this study needed to have normal cycles prior to treatment, and these were confirmed by examination of vaginal smears under a light microscope for two sequential estrous cycles (about 8-10 days). All rats were randomly divided into four groups and treated with (A) an equal volume of saline as controls, (B) $3.0 \mathrm{IU} /$ day hCG to induce hyperandrogenism, (C) insulin, which was started at $0.5 \mathrm{IU} /$ day and gradually increased to $6.0 \mathrm{IU} /$ day between the 11th day and the 22nd day to induce hyperinsulinemia and peripheral insulin resistance, or (D) hCG plus insulin to induce a combination of hyperandrogenism and peripheral insulin resistance, which are key co-pathologies of PCOS. Animals were decapitated on the 23rd day. The doses and treatment protocols for hCG and insulin are described in detail in the previous paper [20].

Prior to treatment, estrous cycles were monitored daily by vaginal lavage according to a standard protocol [51]. Rats treated with saline or insulin had normal cycles, but hCG-treated and hCG+insulintreated animals displayed absent or prolonged cycles. None of the hCG+insulin-treated rats with prolonged estrous cycles were included in the study. After treatment, 10 animals per group were randomly selected and further analyzed.

After transient anesthesia by isoflurane (2\% in a 1:1 mixture of oxygen or air, RWD Life Science Co., Shenzhen, China), the ovaries and uteri were removed and stripped of fat and connective tissues. One side of the ovary and uterus in each animal was fixed in $4 \%$ formaldehyde and neutral buffered solution for $24 \mathrm{~h}$ at $4^{\circ} \mathrm{C}$ and embedded in paraffin for histochemical analysis. The other side was immediately frozen in liquid nitrogen and stored at $-70^{\circ} \mathrm{C}$ for subsequent quantitative real-time (qRT) PCR and Western blot analyses.

\subsection{Morphological assessment, immunostaining, and imaging}

The fixed tissue, including the ovaries and uteri, was embedded in paraffin. Sections were cut at a thickness of $5 \mu \mathrm{m}$ and stained with hematoxylin and eosin (H\&E) according to standard procedures, and the immunohistochemical staining was performed as previously described [47, 48]. Ovarian and 
uterine tissue sections were dewaxed and refixed in Bouin's solution (HT10132, Sigma-Aldrich) and stained with Weigert's Iron Hematoxylin Set (HT10-79, Sigma-Aldrich) and Masson's Trichrome Staining Kit (HT15, Sigma-Aldrich) as described by the manufacturer. After deparaffinization and rehydration, the sections were immersed in epitope retrieval buffer (1 mM EDTA, 0.05\% Tween 20, pH 8.0) and heated in a 700 Watt microwave for $15 \mathrm{~min}$. The sections were subsequently rinsed twice with $\mathrm{dH}_{2} \mathrm{O}$ and once with $0.01 \mathrm{M}$ Tris-buffered saline supplemented with Triton X-100 (TBST). The endogenous peroxidase was removed, and nonspecific binding was blocked by incubation with $3 \%$ $\mathrm{H}_{2} \mathrm{O}_{2}$ for 10 min and then with $10 \%$ normal goat serum for $1 \mathrm{~h}$ at room temperature. After incubation with the anti-GR primary antibody (1:100 dilution, Table 1 ) overnight at $4^{\circ} \mathrm{C}$ in a humidified chamber, sections were stained using the avidin-biotinylated-peroxidase ABC kit according to the manufacture's instructions (Vector Laboratories) followed by a 5-min treatment with 3,3-diaminobenzidine tetrahydrochloride (DAB, SK-4100, Vector Laboratories). All sections were incubated with DAB for the same length of time so that comparisons could be made between individual samples, and all slides were stained in a single run to eliminate inter-experiment variations in staining intensity. Tissue sections were observed with a Nikon E-1000 microscope (Japan) under bright-field optics and photomicrographed using Easy Image 1 (Bergström Instrument AB, Sweden).

\subsection{RNA isolation and $q R T-P C R$ analysis}

The details of ovarian and uterine RNA isolation, quantification, and quality assessment were described previously [20]. Each cDNA sample was subjected to qRT-PCR with a Roche Light Cycler 480 sequence detection system (Roche Diagnostics Ltd., Rotkreuz, Switzerland) using SYBR green qPCR master mix (K0252, Thermo Scientific, Rockford, IL). The primer sequences for each target gene are listed in Table 2. Several housekeeping genes, including Gapdh, Actb, and U87, were tested prior to analysis. Gapdh was chosen as the internal reference for all analyses because expression remained stable across all groups. Each sample was analyzed in triplicate, and the relative fold expression of each gene was calculated using the comparative critical threshold (Ct) method (Life Technologies, Stockholm, Sweden) with normalization to the Gapdh gene based on the $2^{-\Delta \Delta C t}$ calculation.

\subsection{Tissue protein extraction and Western blot analysis}

Ovarian and uterine samples were pulverized and then homogenized in ice-cold RIPA buffer (Sigma-Aldrich) supplemented with complete Mini protease inhibitor cocktail tablets (Roche 
Diagnostics, Mannheim, Germany) and PhosSTOP phosphatase inhibitor cocktail tablets (Roche Diagnostics). The protein extractions for whole cells and mitochondrial fractions were performed following published methodology $[20, \underline{48}, \underline{52}]$. After determining the total protein concentration by BCA assay, $30 \mu \mathrm{g}$ of protein from each group was resolved on 4-20\% TGX stain-free gels (Bio-Rad Laboratories $\mathrm{GmbH}$, Munich, Germany) and transferred onto PVDF membranes. The membranes were blocked by $0.01 \mathrm{M}$ Tris-buffered saline supplemented with Triton X-100 containing $5 \%$ nonfat dry milk for $1 \mathrm{~h}$ and were probed with different primary antibodies (Table 1) in the blocking buffer overnight at $4^{\circ} \mathrm{C}$ followed by HRP-conjugated secondary antibody. Chemiluminiscence signals were detected using SuperSignal West Dura substrate following the manufacturer's instructions (Thermo ScientificPierce). Ultraviolet activation of the Criterion stain-free gel on a ChemiDoc MP Imaging System (BioRad) was used to control for proper loading. Band densitometry and quantification was performed using Image Laboratory (Version 5.0, Bio-Rad, Sweden), and the protein band densities were normalized to the total-protein loading control. Details of the method have been described previously [47].

\subsection{Statistics}

For all experiments, n-values represent the numbers of individual animals. All values are presented as the means \pm SEM. Statistical analyses were performed using the Statistical Package for Social Science (SPSS, version 24.0, SPSS Inc., Chicago, IL) and Graphpad Prism statistical software (Graphpad, version 5.0, Graphpad Software, La Jolla, CA) for Windows. The normal distribution of the data was tested with the Shapiro-Wilk test. Differences between groups were analyzed by one-way ANOVA followed by Tukey's post-hoc test for normally distributed data or by the Kruskal-Wallis test for skewed data. Statistical significance was set at $p<0.05$.

\section{Results}

\subsection{Ovarian defects in rats treated chronically with $h C G$ and/or insulin}

In accordance with previous results from studies of follicular cyst formation and ovarian stromal hyperplasia in rodents treated with hCG and insulin $[22,53]$, we found grossly oversized ovaries with enlarged fluid-filled follicles in hCG+insulin-treated and hCG-treated rats compared to control and insulin-treated rats (Fig. 1A). Further, morphological analysis revealed significant differences in the number of ovarian cystic follicles in hCG+insulin-treated and hCG-treated rats compared with the number in control and insulin-treated rats (Fig. 1A). In the ovaries, weak immunoreactivity was present 
in the cytoplasm of follicle cells (mainly in granulosa cells) and oocytes in control rats; however, there was intense nuclear GR immunoreactivity in the corpus luteum (Fig. 1B). In addition, GR immunoreactivity was almost absent in the apoptotic follicles in control rats (Fig. 1B). Because the GR consists of two distinct isoforms, GRa and GR [11], we performed a Western blot analysis to measure the expression of ovarian GR protein isoforms in rats treated chronically with hCG and/or insulin (Fig. 1C). There was no significant difference in GRa, GRß, or total GR expression between saline-treated and insulin-treated rats. However, we observed that the expression of GR $\alpha$ and GR together with total GR was significantly decreased in hCG-treated rats compared to controls. Quantitative protein data indicated that GRa and total GR, but not GR $\beta$, proteins were decreased in hCG+insulin-treated rats compared to control rats. Because FKBP5 (Fkbp51) and FKBP4 (Fkbp52), the GR binding proteins, display differential regulation of GR activation [54], we compared the expression of Fkbp51 and Fkbp52 mRNAs in the ovary by qRT-PCR (Fig. 1D). Quantitative data indicated that Fkbp51 but not Fkbp52 mRNA levels were increased in rats treated with hCG and/or insulin compared to control rats treated with saline. This result suggests that Fkbp51, a negative regulator of GR activity, might be able to bind GR and block its activation in the ovary. While both $11 \beta H S D 1(H s d 11 b 1)$ and 11ßHSD2 (Hsd11b2) are expressed in the ovary [11, 34], we found that the Hsd11b1 mRNA level was decreased in hCG+insulin-treated and insulin-treated rats compared to controls. In contrast to insulin-treated rats, hCG+insulin-treated and hCG-treated rats exhibited an increase in Hsd11b2 mRNA level (Fig. 1E).

GR function contributes not only to nuclear, but also to mitochondrial transcription [35]. To analyze whether the aberrant regulation of oxidative phosphorylation (OXPHOS) capacity - a key aspect of mitochondrial respiratory function [55] - is associated with decreased GR protein expression in the ovary after treatment with hCG and insulin, we profiled the expression of five respiratory protein complexes (Complex I, NADH dehydrogenase; Complex II, succinate dehydrogenase; Complex III, ubiquinol cytochrome c reductase; Complex IV, cytochrome c oxidase; and Complex V, ATP synthase) in the ovary. As shown in Fig. 2A, similar to GR protein regulation, the expression of OXPHOS Complex I, IV, and V was decreased in hCG+insulin-treated and hCG-treated rats compared to control rats. Among five respiratory protein complexes, only Complex II protein expression was increased in insulin-treated rats compared to control rats treated with saline. Next, we analyzed the gene expression profile, focusing on mitochondrial fusion (Mfn1 and Opa1), fission (Drp1), biogenesis (Tfam, 
Pgc1a, and Nrf1), and mitophagy (Parkin, Pink1, Rheb, and Atp13a) [56]. As shown in Fig. 2B, although no significant difference was seen in Mfn1, Tfam, or Pink1 mRNA expression between hCG+insulin-treated and control rats, increased expression of Opa1, Drp1, and Pgc1a mRNAs and decreased expression of Nrf1, Parkin, Rheb, and Atp13a mRNAs were found in hCG+insulin-treated rats. Additionally, there were similarities and differences in the gene expression patterns between hCG-treated and insulin-treated rats. For instance, we found increased expression of Mfn1 and Opa1 mRNAs and decreased Atp13a mRNA expression in hCG-treated and insulin-treated rats compared to controls. However, Tfam mRNA expression was decreased in hCG-treated rats but was increased in insulin-treated rats. Moreover, Pink1 mRNA expression was unaltered in hCG-treated rats but was decreased in insulin-treated rats. Thus, the lack of significant effects of the combination of hCG and insulin on Tfam and Pink1 mRNA expression is likely due to the contrasting effects of hCG and insulin. Similar to hCG+insulin-treated rats, decreased Rheb mRNA expression and increased Drp1 and Pgc1a mRNA expression were found in both hCG-treated and insulin-treated rats.

A dysfunctional or less sensitive GR promotes NFKB-mediated inflammatory processes [54, $\underline{57}$. Using Western blotting, we found that the expression of the inhibitor of NFkB kinase complex $\beta$ (IKK $\beta$ ) and nuclear factor of kappa light polypeptide gene enhancer in B-cells inhibitor alpha (IKBa) proteins was decreased in hCG+insulin-treated and hCG-treated rats (Fig. 3A). However, we found that while total NFKB (p65) protein expression was decreased, phosphorylated NFKB (p65) protein expression and the ratio of phosphorylated NFKB (p65) [p-NFKB (p65)] to total NFKB (p65) protein levels were significantly higher in hCG+insulin-treated rats than controls. While the pattern of total NFKB (p65) protein expression and the ratio of $\mathrm{p}-\mathrm{NFkB}(\mathrm{p} 65)$ to total NFKB (p65) protein expression between hCG+insulin-treated and hCG-treated rats were similar, no alterations of any protein expression or the ratio of phosphorylated $\mathrm{NFKB}(\mathrm{p} 65)$ to total $\mathrm{NFKB}(\mathrm{p} 65)$ protein expression were found in insulintreated rats (Fig. 3A). We next determined the expression pattern of genes that are involved in the inflammatory process in the ovary by qRT-PCR. Quantitative data indicated that Tnfa, $\|1 b\| 6,, C c / 2$, and Csf2 mRNA expression was decreased by hCG and insulin treatment, both separately and in combination (Fig. 3B). Moreover, while Tnfaip3 mRNA expression was increased in hCG+insulintreated and insulin-treated rats, $\mathrm{Cc} / 5$ mRNA expression was decreased in hCG+insulin-treated rats compared to control rats (Fig. 3B). Collagens are key structural protein components of the extracellular matrix [58], and altered matrix metalloproteinase (MMP) expression plays a role in the 
pathophysiology of the ovary and uterus [59]. In the ovary, we found that compared to control rats Mmp2 mRNA expression was decreased in hCG+insulin-treated and hCG-treated rats and that Mmp3 mRNA expression was decreased by hCG and insulin treatment, both separately and in combination (Fig. 3B). Furthermore, Masson's trichrome staining revealed that the deposition of ovarian collagen was significantly increased in hCG+insulin-treated rats compared to control rats (Fig. 3C). hCG-treated but not insulin-treated rats displayed similar ovarian collagen deposition as hCG+insulin-treated rats (data not shown).

\subsection{Uterine defects in rats treated chronically with $h C G$ and/or insulin}

Consistent with our previous studies $[\underline{20}, \underline{48}]$, the most dilated uterine lumen was seen in hCGtreated rats compared to the other three groups, and multiple cystic glands filled with large amounts of secretory fluid were found in hCG+insulin-treated rats (Fig. 4A). General histological evaluation of the uterine sections stained with H\&E showed that the luminal epithelial cells remained cuboidal with similar thickness in saline-treated and insulin-treated rats, but increased luminal epithelial cell height and the appearance of vacuoles and the formation of multiple cell layers were observed in hCG+insulin-treated and hCG-treated rats (Fig. 4A). In line with previous results [60-62], immunochemical analysis revealed that the luminal and glandular epithelial cells exhibited greater GR immunoreactivity in the cytoplasm compared to the nucleus, which was in contrast to the predominantly nuclear GR expression in stromal cells in control rats (Fig. 4B). In addition, GR immunoreactivity was also observed in the myometrium and blood vessels (Fig. 4B). Quantitative data from Western blot analysis indicated that the expression of GRa and GR $\beta$ together with total GR was significantly decreased in hCG+insulin-treated rats compared to controls; however, no significant difference in GRa, GRß, or total GR expression was found between saline-treated and hCG-treated rats or between saline-treated and insulin-treated rats (Fig. 4C). Similar to the ovary (Fig. 1D), the expression of Fkbp51 mRNA was increased in the rat uterus compared to control rats regardless of whether the rat was treated with hCG, insulin, or a combination of the two (Fig. 4D). Unlike the ovary (Fig. 1D), however, the expression of Fkbp52 mRNA was significantly higher in hCG-treated and insulin-treated rats than control rats (Fig. 4D). Furthermore, quantitative data from qRT-PCR indicated that the Hsd11b1 mRNA level was increased in rats treated with hCG and/or insulin compared to controls, and a decreased Hsd11b2 mRNA level was only seen in hCG-treated rats compared to control rats (Fig. 4E). 
To investigate whether mitochondrial function and homeostasis were altered in the uterus or the ovary in response to hCG and insulin treatment, the expression of five respiratory protein complexes and a set of genes (Mfn1, Opa1, Drp1, Tfam, Pgc1a, Nrf1, Parkin, Pink1, Rheb, and Atp13a) was determined by Western blotting and QRT-PCR. As shown in Fig. 5A, while the expression of OXPHOS Complex I was decreased in hCG+insulin-treated and hCG-treated rats, Complexes III, IV, and V were only decreased in hCG+insulin-treated rats compared to controls rats. There were no significant changes in the five respiratory protein complexes between insulin-treated and control rats. The levels of Mfn1, Opa1, Drp1, Tfam, Pgc1a, Nrf1, Parkin, and Rheb mRNAs, but not Pink1 and Atp13a mRNAs, were increased in hCG+insulin-treated rats compared to controls rats (Fig. 5B). All measured gene levels were increased to some extent in hCG-treated and insulin-treated rats compared to controls, indicating a similar gene expression pattern for hCG and insulin treatment (Fig. 5B).

Similar to the ovary (Fig. 3A), decreased IKK 3 , IKBa, and total NFKB (p65) protein expression and increased $p-N F k B$ (p65) protein expression and increased ratio of $p-N F K B$ (p65) to total NFKB (p65) protein levels were observed in hCG+insulin-treated rats (Fig. 6A). In addition, we observed that while there was no change in any measured protein expression between insulin-treated rats and controls, total NFKB (p65) protein expression was decreased in hCG-treated rats compared to control rats (Fig. 6A). At the same time, increased Tnfa, Tnfaip3, Ccl2, Ccl5, and Mmp3 mRNA expression and decreased $\|1 b\|$,6 , and Mmp2 mRNA expression was observed in hCG+insulin-treated rats (Fig. 6B). Furthermore, while a similar regulatory pattern of Tnfaip3, $\|1 b\|$,6 , and Ccl5 mRNA expression was seen in hCG-treated and insulin-treated rats, the expression of Tnfa, Ccl2, Csf2, Mmp2, and Mmp3 mRNA was either increased or unchanged in hCG-treated rats compared to control rats (Fig. 6B). Lastly, Masson's trichrome staining showed that the deposition of uterine collagen was significantly increased in hCG+insulin-treated and insulin-treated rats compared to control rats, whereas uterine collagen deposition was significantly decreased in hCG-treated rats compared to control rats (Fig. 6C).

\section{Discussion}

Suppression of GR signaling in association with disturbed mitochondrial function and inflammation in the ovary and uterus caused by hyperandrogenism and insulin resistance has never to our knowledge been investigated in vivo. Consistent with previous studies [20, $\underline{22}, \underline{46-48]}$, we found that concomitant treatment with hCG and insulin mimicking the main pathologies of PCOS causes pronounced morphological and cellular alterations in the ovary and uterus such as the formation of 
ovarian cystic follicles and multiple cystic glands filled with large amounts of secretory fluid as well as increased luminal epithelial cell layers. In addition to morphological analyses, we report the following main findings. (1) Compared to controls, PCOS-like rats exhibited decreased protein expression of the two GR isoforms and increased Fkbp51 mRNA expression in both the ovary and the uterus. (2) Cotreatment with hCG and insulin resulted in an opposite regulatory pattern of Hsd11b1 of Hsd11b2 mRNAs in the two tissues, which is likely due to different effects of hCG and insulin. (3) Decreased expression of the respiratory protein complexes parallels the increased expression of key genes responsible for mitochondrial fusion, fission, and biogenesis in both tissues. (4) Increased expression of NFKB signaling proteins and Tnfaip3, as well as decreased expression of $\| 1 \mathrm{~b}$, $\| 6$, and Mmp2 mRNAs was similar in the PCOS-like ovary and uterus, while the opposite regulation of Tnfa, Ccl2, $\mathrm{Ccl} 5$, and Mmp3 mRNA expression was observed in the two tissues under the same conditions. (5) The increase in collagen deposition was similar in the two tissues under conditions of hyperandrogenism and insulin resistance.

In this study, we observed similar regulatory patterns of GR protein isoform expression in both the ovary and uterus after stimulation with hCG and insulin. While elevated E3 ubiquitin ligases, the key component of the ubiquitin-proteasome system for multiple protein stabilization, are critical for the development of insulin resistance [63], Lim and colleagues have reported that increased AR ubiquitination - which results in inhibition of AR transcriptional activity and decreases its stability - is involved in the follicular growth arrest seen in the $5 \alpha$-dihydrotestosterone-induced PCOS-like rat ovary [64]. In addition, alterations in protein ubiquitination has also been reported to have a negative effect on GR expression and activity in vivo [65], and uterine GR knockout studies have shown that GR positively regulates embryo implantation and decidualization [14]. We therefore speculate that downregulation of GR protein levels is due to increased GR ubiquitination under conditions of hyperandrogenism and insulin resistance and that this results in negative consequences such as increased NFKB-regulated inflammation in the ovary and uterus. Because deciphering the molecular mechanisms of hyperandrogenism and insulin resistance in vivo is essential to understanding the possible etiologies and therapeutic approaches for PCOS, further investigations are needed to better understand how GR signaling directly contributes to the development of ovarian and uterine dysfunction in PCOS patients. 
Hu et al./p14

This study further demonstrates the association between two Hsd11b mRNAs and hyperandrogenism and insulin resistance in the rat ovary and uterus. We showed that concomitant treatment with hCG and insulin decreased Hsd11b1 mRNA expression and increased Hsd11b2 mRNA expression in the ovary. In stark contrast to the ovary, the same treatment increased Hsd11b1 mRNA expression but did not change Hsd11b2 mRNA expression in the uterus. Given the opposing roles of Hsd11b1 and Hsd11b2 in the regulation of local active cortisol (corticosterone in rodents) concentrations [34], it is tempting to speculate from these observations that, in contrast to the uterus, the activation of 11-dehydrocorticosterone to corticosterone is decreased in the ovary under conditions of hyperandrogenism and insulin resistance. However, this outcome is quite different to what is seen in the human data. In hyperandrogenic PCOS patients, elevated Hsd11b1 mRNA levels in granulosa cells are closely linked to ovarian insulin resistance, whereas lower Hsd11b2 mRNA and protein levels contribute to endometrial insulin resistance [23, 24]. Despite the presence of similar, different, or even opposite regulation and localization of the two $11 \beta \mathrm{HSD}$ isoforms in the ovarian and endometrial cells $[10,11,34]$, evidence for their physiological roles in the ovary and uterus is lacking. Additionally, there are differences in the regulation of ovarian hormone receptors such as AR between PCOS patients and PCOS-like animal models [66]. Although abnormal cortisol metabolism has been shown in some PCOS patients [29, 30], GR can be activated by estrogens in addition to glucocorticoids in the uterus [11]. However, because our findings are from observing only a single time point, the possibility that aberrant regulation of the two Hsd11b isoform mRNAs depends on local endocrine environments in the ovary and uterus during the progression of hyperandrogenism and insulin resistance remains entirely speculative.

Mitochondria are essential not only for generation of ATP by aerobic respiration, but also for steroidogenesis through mitochondrial cholesterol transport and metabolism [67]. Although the precise mechanism underlying mitochondria-regulated ovarian and uterine cell function is uncertain, impaired mitochondrial function is seen in PCOS patients and PCOS-like animals [26, $\underline{39-45}$. We found that rats co-treated with hCG and insulin had reduced levels of OXPHOS-related proteins (NADH dehydrogenase, cytochrome c oxidase, and ATP synthase) in the ovary and uterus. This observation indicates that the mitochondrial respiratory capacity was affected by hyperandrogenism and insulin resistance, thus suggesting that these conditions cause the mitochondria-mediated metabolic defects seen in the two tissues. Unexpectedly, in parallel to the GR down-regulation, the same animals 
413 exhibited increased expression of genes involved in mitochondrial fusion (Opa1), fission (Drp1), and biogenesis (Pgc1a) in both tissues. In addition, we also showed that expression of the mitophagic genes Parkin and Rheb was decreased in the ovary, whereas the same gene expression was increased in the uterus. Healthy mitochondrial function is dependent on the fusion-fission cycle, while damaged and unwanted mitochondria are removed by mitophagy [56]. Based on qRT-PCR and Western blot analyses using the ovarian and uterine homogenates, we cannot rule out the possibility that different mechanisms are responsible for RNA turnover and translational control of protein turnover and abundance in the ovary and uterus in response to the hormonal milieu [20, $\underline{40}$. However,

421 it is worth noting that the decrease in mitochondrial respiratory capacity might stimulate the mitochondrial fusion-fission cycle and biogenesis through a complementary or adaptive effect during the progression of hyperandrogenism and insulin resistance.

Although GR acts as both an enhancer and inhibitor for controlling a large number of transcriptional pathways, diverse mechanistic models have been proposed for the specific effects of GR repression on NFKB activity in vitro [54, 57]. We highlight how the conditions of hyperandrogenism and insulin resistance suppressed GR protein expression and activated NFKB signaling in the ovary and uterus. Numerous clinical studies have reported that androgen excess, hyperinsulinemia, and systemic inflammation often co-exist in PCOS patients [72]. Notably, PCOS patients display significant activation of NFKB signaling in association with elevated inflammation in ovarian granulosa cells and endometrial cells [68-70]. Despite the overlapping and distinct cytokine and chemokine gene expression between the ovary and uterus, PCOS-like rats showed aberrant regulation of $\mathrm{Mmp2}$ and Mmp3 mRNAs leading to increased collagen deposition in both tissues. In line with our findings, Henmi and colleagues have reported that elevated ovarian Mmp2 protein expression modulates collagen synthesis in dehydroepiandrosterone-induced PCOS-like rats [71]. Taken together, the present study suggests that the GR-NFKB signaling axis probably plays a contributing role in triggering chronic inflammation ultimately resulting in ovarian and uterine dysfunction under the conditions of hyperandrogenism and insulin resistance. Our understanding of the molecular mechanism and biological function of GR has increased. However, why and when the suppression of GR signaling induced ovarian and uterine dysfunctions in PCOS warrants further investigation. 
443 homeostasis as well as NFKB-regulated inflammation in the rat ovary and uterus. Of note, the opposite

444 regulation between OXPHOS proteins and genes that act as the key regulators for mitochondrial 445 fusion, fission, and biogenesis in PCOS-like rats suggests that such compensatory or adaptive 446 mechanisms probably help protect ovarian and uterine cells against hyperandrogenism and insulin 447 resistance-induced damage. Given the fact that no means exist to predict or prevent the onset and 448 lifelong consequences of PCOS in humans [66], the identification of the relationships between 449 different molecular mechanisms and PCOS phenotypes, including elucidation of the regulation of GR 450 signaling under conditions of hyperandrogenism and insulin resistance, will provide insights into how 451 ovarian and uterine cells respond and adapt to the pathological conditions of PCOS. 
453 Author Contributions: Conceptualization, supervision, and original draft, LRS; methodology and

454

455

456

457

458

459

460

461

462

463

464

465

466

467

468

469

470

471

472

473

474 investigation, MH, YZ, XG, WJ, GL, JZ, PC, JL, WL, and LRS; writing - review and editing, MB, LRS, and HB; scientific oversight and guidance, XW, HM, MB, LRS, and HB. All authors have read and approved the final version of the manuscript.

Acknowledgments: This study was financed by grants from the Swedish Medical Research Council (grant number 10380), the Swedish state under the agreement between the Swedish government and the county councils-the ALF-agreement (grant number ALFGBG-147791), Jane and Dan Olsson's Foundation, the Knut and Alice Wallenbergs Foundation, and the Adlerbert Research Foundation to HB and LRS as well as by grants from the National Natural Science Foundation of China (grant number 81774136), the Project of Science Foundation by Heilongjiang University of Chinese Medicine, the Project of Excellent Innovation Talents by Heilongjiang University of Chinese Medicine, and the Science Initiation Foundation for Post-doctoral Researchers Settled in Heilongjiang Province to YZ. The Guangzhou Medical University High-level University Construction Talents Fund (grant number B185006010046) supported MH.

Conflicts of Interest: The authors indicate no potential conflicts of interest.

Abbreviations: Fkbp51, FK506 binding protein 5; GR, glucocorticoid receptor; Hsd11b, 11ßhydroxysteroid dehydrogenase; IKBa, nuclear factor of kappa light polypeptide gene enhancer in Bcells inhibitor alpha; IKK , inhibitor of NFkB kinase complex $\beta$; Mmp2, matrix metallopeptidase 2; NFKB, nuclear factor kappa-light-chain-enhancer of activated B cells; Nrf1, nuclear respiratory factor 1; OXPHOS, oxidative phosphorylation; PCOS, polycystic ovary syndrome; Pgc1a, peroxisome proliferator-activated receptor gamma coactivator 1 alpha; Tfam, mitochondrial transcription factor A; Tnfa, tumor necrosis factor alpha. 
Hu et al./p18

\section{References}

1. Lizneva, D.; Suturina, L.; Walker, W.; Brakta, S.; Gavrilova-Jordan, L.; Azziz, R., Criteria, prevalence, and phenotypes of polycystic ovary syndrome. Fertil Steril 2016, 106, (1), 6 - 15.

2. Li, X.; Feng, Y.; Lin, J. F.; Billig, H.; Shao, R., Endometrial progesterone resistance and PCOS. J Biomed Sci 2014, 21, (1), 2.

3. Cooney, L. G.; Dokras, A., Beyond fertility: polycystic ovary syndrome and long-term health. Fertil Steril 2018, 110, (5), 794-809.

4. Shao, R.; Li, X.; Feng, Y.; Lin, J. F.; Billig, H., Direct effects of metformin in the endometrium: a hypothetical mechanism for the treatment of women with PCOS and endometrial carcinoma. $\mathrm{J}$ Exp Clin Cancer Res 2014, 33, 41.

5. Homburg, R., Management of infertility and prevention of ovarian hyperstimulation in women with polycystic ovary syndrome. Best Pract Res Clin Obst Gynaecol 2004, 18, (5), 773-88.

6. Chakraborty, P.; Goswami, S. K.; Rajani, S.; Sharma, S.; Kabir, S. N.; Chakravarty, B.; Jana, $\mathrm{K}$., Recurrent pregnancy loss in polycystic ovary syndrome: role of hyperhomocysteinemia and insulin resistance. PLoS One 2013, 8, (5), e64446.

7. Rosenfield, R. L.; Ehrmann, D. A., The Pathogenesis of Polycystic Ovary Syndrome (PCOS): The Hypothesis of PCOS as Functional Ovarian Hyperandrogenism Revisited. Endocr Rev 2016, 37, (5), 467-520.

8. $\quad$ Azziz, R.; Carmina, E.; Chen, Z.; Dunaif, A.; Laven, J. S.; Legro, R. S.; Lizneva, D.; NattersonHorowtiz, B.; Teede, H. J.; Yildiz, B. O., Polycystic ovary syndrome. Nat Rev Dis Primers 2016, 2, 16057.

9. Escobar-Morreale, H. F., Polycystic ovary syndrome: definition, aetiology, diagnosis and treatment. Nat Rev Endocrinol 2018, 14, (5), 270-284.

10. Whirledge, S.; DeFranco, D. B., Glucocorticoid Signaling in Health and Disease: Insights From Tissue-Specific GR Knockout Mice. Endocrinology 2018, 159, (1), 46-64.

11. Whirledge, S.; Cidlowski, J. A., A role for glucocorticoids in stress-impaired reproduction: beyond the hypothalamus and pituitary. Endocrinology 2013, 154, (12), 4450-68.

12. Tetsuka, M., Actions of glucocorticoid and their regulatory mechanisms in the ovary. Anim Sci J 2007, 78, (2), 112-120.

13. Critchley, H. O.; Saunders, P. T., Hormone receptor dynamics in a receptive human endometrium. Reprod Sci 2009, 16, (2), 191-9.

14. Whirledge, S. D.; Oakley, R. H.; Myers, P. H.; Lydon, J. P.; DeMayo, F.; Cidlowski, J. A., Uterine glucocorticoid receptors are critical for fertility in mice through control of embryo implantation and decidualization. Proc Natl Acad Sci U S A 2015, 112, (49), 15166-71.

15. Zhou, P. Z.; Zhu, Y. M.; Zou, G. H.; Sun, Y. X.; Xiu, X. L.; Huang, X.; Zhang, Q. H., Relationship Between Glucocorticoids and Insulin Resistance in Healthy Individuals. Med Sci Monit 2016, 22, 1887-94.

16. Kuo, T.; McQueen, A.; Chen, T. C.; Wang, J. C., Regulation of Glucose Homeostasis by Glucocorticoids. Adv Exp Med Biol 2015, 872, 99-126.

17. Belani, M.; Purohit, N.; Pillai, P.; Gupta, S.; Gupta, S., Modulation of steroidogenic pathway in rat granulosa cells with subclinical $\mathrm{Cd}$ exposure and insulin resistance: an impact on female fertility. BioMed Res Int 2014, 2014, 460251.

18. Hackbart, K. S.; Cunha, P. M.; Meyer, R. K.; Wiltbank, M. C., Effect of glucocorticoid-induced insulin resistance on follicle development and ovulation. Biol Reprod 2013, 88, (6), 153.

19. Kong, L.; Wang, Q.; Jin, J.; Xiang, Z.; Chen, T.; Shen, S.; Wang, H.; Gao, Q.; Wang, Y., Insulin resistance enhances the mitogen-activated protein kinase signaling pathway in ovarian granulosa cells. PLoS One 2017, 12, (11), e0188029.

20. Zhang, Y.; Sun, X.; Sun, X.; Meng, F.; Hu, M.; Li, X.; Li, W.; Wu, X. K.; Brännström, M.; Shao, R.; Billig, H., Molecular characterization of insulin resistance and glycolytic metabolism in the rat uterus. Sci Rep 2016, 6, 30679.

21. Andrisse, S.; Billings, K.; Xue, P.; Wu, S., Insulin signaling displayed a differential tissuespecific response to low-dose dihydrotestosterone in female mice. Am J Physiol Endocrinol Metab 2018, 314, (4), E353-E365.

22. Restuccia, D. F.; Hynx, D.; Hemmings, B. A., Loss of PKBbeta/Akt2 predisposes mice to ovarian cyst formation and increases the severity of polycystic ovary formation in vivo. Dis Mod Mech 2012, 5, (3), 403-11.

23. Qi, J.; Wang, W.; Zhu, Q.; He, Y.; Lu, Y.; Wang, Y.; Li, X.; Chen, Z. J.; Sun, Y., Local Cortisol Elevation Contributes to Endometrial Insulin Resistance in Polycystic Ovary Syndrome. J Clin Endocrinol Metab 2018, 103, (7), 2457-2467. 
24. Zhu, Q.; Zuo, R.; He, Y.; Wang, Y.; Chen, Z. J.; Sun, Y.; Sun, K., Local Regeneration of Cortisol by 11beta-HSD1 Contributes to Insulin Resistance of the Granulosa Cells in PCOS. J Clin Endocrinol Metab 2016, 101, (5), 2168-77.

25. Li, X.; Pishdari, B.; Cui, P.; Hu, M.; Yang, H. P.; Guo, Y. R.; Jiang, H. Y.; Feng, Y.; Billig, H.; Shao, R., Regulation of androgen receptor expression alters AMPK phosphorylation in the endometrium: in vivo and in vitro studies in women with polycystic ovary syndrome. Int $\mathrm{J}$ Bio Sci 2015, 11, (12), 1376-89.

26. Wang, T.; Zhang, J.; Hu, M.; Zhang, Y.; Cui, P.; Li, X.; Li, J.; Vestin, E.; Brannstrom, M.; Shao, L. R.; Billig, H., Differential Expression Patterns of Glycolytic Enzymes and MitochondriaDependent Apoptosis in PCOS Patients with Endometrial Hyperplasia, an Early Hallmark of Endometrial Cancer, In Vivo and the Impact of Metformin In Vitro. Int J Biol Sci 2019, 15, (3), 714-725.

27. Dewailly, D.; Robin, G.; Peigne, M.; Decanter, C.; Pigny, P.; Catteau-Jonard, S., Interactions between androgens, FSH, anti-Mullerian hormone and estradiol during folliculogenesis in the human normal and polycystic ovary. Hum Reprod Update 2016, 22, (6), 709-724.

28. Claessens, F.; Joniau, S.; Helsen, C., Comparing the rules of engagement of androgen and glucocorticoid receptors. Cell Mol Life Sci 2017, 74, (12), 2217-2228.

29. Tsilchorozidou, T.; Honour, J. W.; Conway, G. S., Altered cortisol metabolism in polycystic ovary syndrome: insulin enhances 5alpha-reduction but not the elevated adrenal steroid production rates. J Clin Endocrinol Metab 2003, 88, (12), 5907-13.

30. Vassiliadi, D. A.; Barber, T. M.; Hughes, B. A.; McCarthy, M. I.; Wass, J. A.; Franks, S.; Nightingale, P.; Tomlinson, J. W.; Arlt, W.; Stewart, P. M., Increased 5 alpha-reductase activity and adrenocortical drive in women with polycystic ovary syndrome. J Clin Endocrinol Metab 2009, 94, (9), 3558-66.

31. Gambineri, A.; Fanelli, F.; Tomassoni, F.; Munarini, A.; Pagotto, U.; Andrew, R.; Walker, B. R.; Pasquali, R., Tissue-specific dysregulation of 11beta-hydroxysteroid dehydrogenase type 1 in overweight/obese women with polycystic ovary syndrome compared with weight-matched controls. Eur J Endocrinol 2014, 171, (1), 47-57.

32. Gathercole, L. L.; Lavery, G. G.; Morgan, S. A.; Cooper, M. S.; Sinclair, A. J.; Tomlinson, J. W.; Stewart, P. M., 11beta-Hydroxysteroid dehydrogenase 1: translational and therapeutic aspects. Endocr Rev 2013, 34, (4), 525-55.

33. Svendsen, P. F.; Madsbad, S.; Nilas, L.; Paulsen, S. K.; Pedersen, S. B., Expression of 11beta-hydroxysteroid dehydrogenase 1 and 2 in subcutaneous adipose tissue of lean and obese women with and without polycystic ovary syndrome. Int J Obes 2009, 33, (11), 1249-56.

34. Chapman, K.; Holmes, M.; Seckl, J., 11beta-hydroxysteroid dehydrogenases: intracellular gate-keepers of tissue glucocorticoid action. Physiol Rev 2013, 93, (3), 1139-206.

35. Lapp, H. E.; Bartlett, A. A.; Hunter, R. G., Stress and glucocorticoid receptor regulation of mitochondrial gene expression. J Mol Endocrinol 2019, 62, (2), R121-R128.

36. Benkhalifa, M.; Ferreira, Y. J.; Chahine, H.; Louanjli, N.; Miron, P.; Merviel, P.; Copin, H., Mitochondria: participation to infertility as source of energy and cause of senescence. Int $\mathrm{J}$ Biochem Cell Biol 2014, 55, 60-4.

37. Hunter, R. G.; Seligsohn, M.; Rubin, T. G.; Griffiths, B. B.; Ozdemir, Y.; Pfaff, D. W.; Datson, N. A.; McEwen, B. S., Stress and corticosteroids regulate rat hippocampal mitochondrial DNA gene expression via the glucocorticoid receptor. Proc Natl Acad Sci U S A 2016, 113, (32), 9099-104.

38. Psarra, A. M.; Sekeris, C. E., Glucocorticoids induce mitochondrial gene transcription in HepG2 cells: role of the mitochondrial glucocorticoid receptor. Biochim Biophys Acta 2011, 1813, (10), 1814-21.

39. Ding, Y.; Jiang, Z.; Xia, B.; Zhang, L.; Zhang, C.; Leng, J., Mitochondria-targeted antioxidant therapy for an animal model of PCOS-IR. Int J Mol Med 2019, 43, (1), 316-324.

40. Hu, M.; Zhang, Y.; Guo, X.; Jia, W.; Liu, G.; Zhang, J.; Li, J.; Cui, P.; Sferruzzi-Perri, A. N.; Han, Y.; Wu, X.; Ma, H.; Brannstrom, M.; Shao, L. R.; Billig, H., Hyperandrogenism and insulin resistance induce gravid uterine defects in association with mitochondrial dysfunction and aberrant ROS production. Am J Physiol Endocrinol Metab 2019. In press

41. Zhang, Y.; Meng, F.; Sun, X.; Sun, X.; Hu, M.; Cui, P.; Vestin, E.; Li, X.; Li, W.; Wu, X. K.; Jansson, J. O.; Shao, L. R.; Billig, H., Hyperandrogenism and insulin resistance contribute to hepatic steatosis and inflammation in female rat liver. Oncotarget 2018, 9, (26), 18180-18197.

42. Cree-Green, M.; Rahat, H.; Newcomer, B. R.; Bergman, B. C.; Brown, M. S.; Coe, G. V.; Newnes, L.; Garcia-Reyes, Y.; Bacon, S.; Thurston, J. E.; Pyle, L.; Scherzinger, A.; Nadeau, K. 
J., Insulin Resistance, Hyperinsulinemia, and Mitochondria Dysfunction in Nonobese Girls With Polycystic Ovarian Syndrome. J Endocrine Soc 2017, 1, (7), 931-944.

43. Wang, H.; Wang, X.; Zhu, Y.; Chen, F.; Sun, Y.; Han, X., Increased androgen levels in rats impair glucose-stimulated insulin secretion through disruption of pancreatic beta cell mitochondrial function. J Steroid Biochem Mol Biol 2015, 154, 254-66.

44. Zhao, H.; Zhao, Y.; Li, T.; Li, M.; Li, J.; Li, R.; Liu, P.; Yu, Y.; Qiao, J., Metabolism alteration in follicular niche: The nexus among intermediary metabolism, mitochondrial function, and classic polycystic ovary syndrome. Free Rad Biol Med 2015, 86, 295-307.

45. Selen, E. S.; Bolandnazar, Z.; Tonelli, M.; Butz, D. E.; Haviland, J. A.; Porter, W. P.; AssadiPorter, F. M., NMR Metabolomics Show Evidence for Mitochondrial Oxidative Stress in a Mouse Model of Polycystic Ovary Syndrome. J Proteome Res 2015, 14, (8), 3284-91.

46. Lima, M. H.; Souza, L. C.; Caperuto, L. C.; Bevilacqua, E.; Gasparetti, A. L.; Zanuto, R.; Saad, M. J.; Carvalho, C. R., Up-regulation of the phosphatidylinositol 3-kinase/protein kinase B pathway in the ovary of rats by chronic treatment with hCG and insulin. $J$ Endocrinol 2006, 190, (2), 451-9.

47. Hu, M.; Zhang, Y.; Feng, J.; Xu, X.; Zhang, J.; Zhao, W.; Guo, X.; Li, J.; Vestin, E.; Cui, P.; Li, X.; Wu, X. K.; Brannstrom, M.; Shao, L. R.; Billig, H., Uterine progesterone signaling is a target for metformin therapy in PCOS-like rats. J Endocrinol 2018, 237, (2), 123-137.

48. Zhang, Y.; Hu, M.; Meng, F.; Sun, X.; Xu, H.; Zhang, J.; Cui, P.; Morina, N.; Li, X.; Li, W.; Wu, X. K.; Brannstrom, M.; Shao, R.; Billig, H., Metformin Ameliorates Uterine Defects in a Rat Model of Polycystic Ovary Syndrome. EBioMedicine 2017, 18, 157-170.

49. Chen, Y.; Qiao, J.; Yan, L. Y.; Huang, S.; Zhao, P. L.; Yan, J., Selective impairment in glycogen synthase kinase-3 and mitogen-activated protein kinase phosphorylation: comparisons with the hyperandrogenic and the hyperinsulinemic rats. Fertil Steril 2009, 92, (4), 1447-55.

50. Li, H.; Chen, Y.; Yan, L. Y.; Qiao, J., Increased expression of P450scc and CYP17 in development of endogenous hyperandrogenism in a rat model of PCOS. Endocrine 2013, 43, (1), 184-90.

51. Feng, Y.; Weijdegard, B.; Wang, T.; Egecioglu, E.; Fernandez-Rodriguez, J.; Huhtaniemi, I.; Stener-Victorin, E.; Billig, H.; Shao, R., Spatiotemporal expression of androgen receptors in the female rat brain during the oestrous cycle and the impact of exogenous androgen administration: a comparison with gonadally intact males. Mol Cell Endocrinol 2010, 321, (2), 161-74.

52. Razmara, A.; Duckles, S. P.; Krause, D. N.; Procaccio, V., Estrogen suppresses brain mitochondrial oxidative stress in female and male rats. Brain research 2007, 1176, 71-81.

53. Kuscu, N. K.; Koyuncu, F.; Ozbilgin, K.; Inan, S.; Tuglu, I.; Karaer, O., Insulin: does it induce follicular arrest in the rat ovary? Gynecol Endocrinol 2002, 16, (5), 361-4.

54. Bekhbat, M.; Rowson, S. A.; Neigh, G. N., Checks and balances: The glucocorticoid receptor and NFkB in good times and bad. Frontiers in neuroendocrinology 2017, 46, 15-31.

55. Huttemann, M.; Lee, I.; Pecinova, A.; Pecina, P.; Przyklenk, K.; Doan, J. W., Regulation of oxidative phosphorylation, the mitochondrial membrane potential, and their role in human disease. J Bioenerg Biomembr 2008, 40, (5), 445-56.

56. Ploumi, C.; Daskalaki, I.; Tavernarakis, N., Mitochondrial biogenesis and clearance: a balancing act. FEBS J 2017, 284, (2), 183-195.

57. Reichardt, H. M.; Tuckermann, J. P.; Gottlicher, M.; Vujic, M.; Weih, F.; Angel, P.; Herrlich, P.; Schutz, G., Repression of inflammatory responses in the absence of DNA binding by the glucocorticoid receptor. EMBO J 2001, 20, (24), 7168-73.

58. Amar, S.; Smith, L.; Fields, G. B., Matrix metalloproteinase collagenolysis in health and disease. Biochimica et biophysica acta. Mol Cell Res 2017, 1864, (11 Pt A), 1940-1951.

59. Endo, T.; Kiya, T.; Goto, T.; Henmi, H.; Manase, K.; Honnma, H.; Baba, T.; Ishioka, S.; Hayashi, T.; Chida, M.; Arima, K.; Yamazaki, K.; Kanaya, M.; Azumaguchi, A.; Moriwaka, O.; Kamiya, H.; Saito, T., Significance of matrix metalloproteinases in the pathophysiology of the ovary and uterus. Reprod Med Biol 2006, 5, (4), 235-243.

60. Burton, P. J.; Dharmarajan, A. M.; Hisheh, S.; Waddell, B. J., Induction of myometrial 11betahydroxysteroid dehydrogenase type 1 messenger ribonucleic acid and protein expression late in rat pregnancy. Endocrinology 1996, 137, (12), 5700-6.

61. Rhen, T.; Grissom, S.; Afshari, C.; Cidlowski, J. A., Dexamethasone blocks the rapid biological effects of 17 beta-estradiol in the rat uterus without antagonizing its global genomic actions. FASEB J 2003, 17, (13), 1849-70. 
62. Gunin, A. G.; Emelianov, V. U.; Tolmachev, A. S., Expression of estrogen receptor-alpha, glucocorticoid receptor, beta-catenin and glycogen synthase kinase-3beta in the uterus of mice following long-term treatment with estrogen and glucocorticoid hormones. Eur J Obstet Gynecol Reprod Biol 2003, 107, (1), 62-7.

63. Yang, X. D.; Xiang, D. X.; Yang, Y. Y., Role of E3 ubiquitin ligases in insulin resistance. Diabetes Obesity Metab 2016, 18, (8), 747-54

64. Lim, J. J.; Lima, P. D. A.; Salehi, R.; Lee, D. R.; Tsang, B. K., Regulation of androgen receptor signaling by ubiquitination during folliculogenesis and its possible dysregulation in polycystic ovarian syndrome. Sci Rep 2017, 7, (1), 10272.

65. Weikum, E. R.; Knuesel, M. T.; Ortlund, E. A.; Yamamoto, K. R., Glucocorticoid receptor control of transcription: precision and plasticity via allostery. Nat Rev Mol Cell Biol 2017, 18, (3), 159-174.

66. Puttabyatappa, M.; Padmanabhan, V., Ovarian and Extra-Ovarian Mediators in the Development of Polycystic Ovary Syndrome. J Mol Endocrinol 2018, 61, (4), R161-R184.

67. Elustondo, P.; Martin, L. A.; Karten, B., Mitochondrial cholesterol import. Biochimica et biophysica acta. Mol Cell Biol Lip 2017, 1862, (1), 90-101.

68. Zhao, Y.; Zhang, C.; Huang, Y.; Yu, Y.; Li, R.; Li, M.; Liu, N.; Liu, P.; Qiao, J., Up-regulated expression of WNT5a increases inflammation and oxidative stress via PI3K/AKT/NF-kappaB signaling in the granulosa cells of PCOS patients. J Clin Endocrinol Metab 2015, 100, (1), 201-11.

69. Koc, O.; Ozdemirici, S.; Acet, M.; Soyturk, U.; Aydin, S., Nuclear factor-kappaB expression in the endometrium of normal and overweight women with polycystic ovary syndrome. $\mathrm{J}$ Obs Gynaecol 2017, 37, (7), 924-930.

70. Orostica, L.; Astorga, I.; Plaza-Parrochia, F.; Vera, C.; Garcia, V.; Carvajal, R.; Gabler, F.; Romero, C.; Vega, M., Proinflammatory environment and role of TNF-alpha in endometrial function of obese women having polycystic ovarian syndrome. Int J Obes 2016, 40, (11), 1715-1722.

71. Henmi, H.; Endo, T.; Nagasawa, K.; Hayashi, T.; Chida, M.; Akutagawa, N.; Iwasaki, M.; Kitajima, Y.; Kiya, T.; Nishikawa, A.; Manase, K.; Kudo, R., Lysyl oxidase and MMP-2 expression in dehydroepiandrosterone-induced polycystic ovary in rats. Biol Reprod 2001, 64, (1), 157-62. 
Hu et al./p22

684

685

686

687

688

689

690

691

692

693

694

695

696

697

698

699

700

701

702

703

704

705

706

707

708

709

710

711

712

713

\section{Figure Legend}

Figure 1. Ovarian defects and impaired GR, Fkbp5, and Hsd11b expression in rats treated chronically with hCG and/or insulin. (A) Representative photographs of ovaries and images of H\&E staining in the ovary. The stars indicate the ovarian cystic follicles. Scale bar, $200 \mu \mathrm{m}$. (B) Representative photomicrographs of immunohistochemical staining for ovarian GR in control rats. PF, primary follicle; AnF, antral follicle; CL, corpus luteum; ApF, apoptotic follicle. Scale bar, $100 \mu \mathrm{m}$. (C) Regulation of GR protein expression in the ovary. Protein levels were analyzed by Western blotting ( $\mathrm{n}$ = 9/group). (D and E) Regulation of Fkbp5 and Hsd11b gene expression in the ovary. mRNA levels were determined by qRT-PCR $(n=6 /$ group $)$. In all plots, data are presented as means \pm SEM. * $p<$ $0.05,{ }^{* *} p<0.01$

Figure 2. Alteration of ovarian mitochondrial OXPHOS protein expression and key mitochondrial-related gene expression in rats treated chronically with hCG and/or insulin. (A) Regulation of OXPHOS protein expression in the ovary. Protein levels were analyzed by Western blotting ( $n=9 /$ group). (B) Regulation of genes that are related to mitochondrial fusion and fission, transcriptional activation, and mitophagy in the ovary. mRNA levels were determined by qRT-PCR $(n=$ 6/group). In all plots, data are presented as means \pm SEM. ${ }^{*} p<0.05,{ }^{* *} p<0.01,{ }^{* *} p<0.001$.

Figure 3. Impaired ovarian NF-KB signaling mediated inflammation and collagen production in rats treated chronically with hCG and/or insulin. (A) Regulation of NF-KB signaling-related protein expression in the ovary. Protein levels were analyzed by Western blotting ( $n=9 /$ group). (B) Regulation of inflammatory gene expression in the ovary. mRNA levels were determined by qRT-PCR ( $n=6$ /group). In all plots, data are presented as means \pm SEM. ${ }^{*} p<0.05,{ }^{* \star} p<0.01,{ }^{\star \star *} p<0.001$.

(C) Collagen production in the ovary. Representative images of Masson's trichrome staining in ovaries collected from rats treated with hCG and insulin. Aniline blue indicates collagen staining. PF, primary follicle; ApF, apoptotic follicle; CL, corpus luteum; GC, granulosa cells; TC, theca cells; IntC, interstitial cells. Scale bar, $100 \mu \mathrm{m}$.

Figure 4. Uterine defects and impaired GR, Fkbp5, and Hsd11b expression in rats treated chronically with hCG and/or insulin. (A) Representative photographs of uteri and images of H\&E staining in the uterus. Scale bar, $200 \mu \mathrm{m}$. (B) Representative photomicrographs of immunohistochemical staining for uterine GR in control rats. Arrows indicate the uterine blood vessels. Le, luminal epithelial cells; G, glands; Ge, glandular epithelial cells; Str, stromal cells; M, myometrium. 
Hu et al./p23

714 Scale bar, $100 \mu \mathrm{m}$. (C) Regulation of GR protein expression in the uterus. Protein levels were

715

716

717

718

719

720

721

722

723

724

725

726

727

728

729

730

731

analyzed by Western blotting ( $\mathrm{n}=8$ or 9/group). (D and E) Regulation of Fkbp5 and Hsd11b gene expression in the uterus. mRNA levels were determined by qRT-PCR $(n=8 /$ group $)$. In all plots, data are presented as means \pm SEM. ${ }^{*} p<0.05,{ }^{* *} p<0.01$.

Figure 5. Alteration of uterine mitochondrial OXPHOS protein expression and key mitochondrial-related gene expression in rats treated chronically with hCG and/or insulin. (A) Regulation of OXPHOS protein expression in the uterus. Protein levels were analyzed by Western blotting ( $n=8$ or 9/group). (B) Regulation of genes that are related to mitochondrial fusion and fission, transcriptional activation, and mitophagy in the uterus. mRNA levels were determined by qRT-PCR ( $\mathrm{n}$ $=8 /$ group). In all plots, data are presented as means \pm SEM. ${ }^{*} p<0.05,{ }^{* \star} p<0.01,{ }^{* * *} p<0.001$.

Figure 6. Impaired uterine NF-KB signaling mediated inflammation and collagen production in rats treated chronically with hCG and/or insulin. (A) Regulation of NF-KB signaling-related protein expression in the uterus. Protein levels were analyzed by Western blotting ( $n=8$ or 9/group). (B) Regulation of inflammation-related gene expression in the uterus. mRNA levels were determined by qRT-PCR $\left(n=8 /\right.$ group). In all plots, data are presented as means \pm SEM. ${ }^{*} p<0.05,{ }^{* *} p<0.01,{ }^{* * *} p$ $<0.001$. (C) Collagen production in the uterus. Representative images of Masson's trichrome staining in ovaries collected from rats treated with hCG and insulin. Aniline blue indicates collagen staining. Ge, glandular epithelial cells; Str, stromal cells; M, myometrium. Scale bar, $100 \mu \mathrm{m}$. 
Table 1. The species, catalog number, method, dilution and source of antibodies

\begin{tabular}{|c|c|c|c|c|c|c|}
\hline Antibody & Species & Code & kDa & Method & Dilution & Source \\
\hline \multirow[t]{2}{*}{ GR } & Rabbit & 3660 & $94 / 91$ & WB & $1: 1000$ & Cell Signaling Technology \\
\hline & & & & IHC & $1: 100$ & (Danver, MA) \\
\hline \multirow[t]{5}{*}{ Total OXPHOS } & Mouse & 110413 & I 20 & WB & $1: 500$ & Abcam (Cambridge, UK) \\
\hline & & & II 30 & & & \\
\hline & & & III 48 & & & \\
\hline & & & IV 40 & & & \\
\hline & & & V 55 & & & \\
\hline $\operatorname{IKK} \beta$ & Rabbit & 8943 & 87 & WB & 1:1000 & Cell Signaling Technology \\
\hline $\mathrm{I} \kappa \mathrm{B} \alpha$ & Mouse & 4814 & 39 & WB & 1:1000 & Cell Signaling Technology \\
\hline p-NF-кB p65 & Rabbit & 3033 & 65 & WB & $1: 500$ & Cell Signaling Technology \\
\hline NF-кB p65 & Rabbit & 8242 & 65 & WB & $1: 1000$ & Cell Signaling Technology \\
\hline
\end{tabular}

GR, glucocorticoid receptor; Total OXPHOS, total oxidative phosphorylation; IKK $\beta$, IkappaB kinase $\beta$; I $\mathrm{I} \mathrm{B} \alpha$, nuclear factor of kappa light polypeptide gene enhancer in B-cells inhibitor alpha; $\mathrm{p}-\mathrm{NF}-\kappa \mathrm{B}$, phosphorylation of nuclear factor kappa-light-chain-enhancer of activated $\mathrm{B}$ cells; WB, Western blot; IHC, immunohistochemistry. 
Table 2. Primer sequences used for qRT-PCR measurement

\begin{tabular}{|c|c|c|c|}
\hline Gene & \multicolumn{2}{|c|}{ Primer Sequence (5'-3’) } & \multirow{2}{*}{$\begin{array}{l}\text { Product Size (bp) } \\
174\end{array}$} \\
\hline Fkbp51 (Fkbp5) & $\begin{array}{l}\text { Forward } \\
\text { Reverse }\end{array}$ & $\begin{array}{l}\text { TTTTGGAGAAGCGGGGAAAC } \\
\text { CСТCССTTGAAGTACACCGT }\end{array}$ & \\
\hline Fkbp52 (Fkbp4) & $\begin{array}{l}\text { Forward } \\
\text { Reverse }\end{array}$ & $\begin{array}{l}\text { GCTGCCATCGAAAGCTGTAA } \\
\text { GTCAAAGTCATTCACGGCCA }\end{array}$ & 102 \\
\hline Hsd11b1 & $\begin{array}{l}\text { Forward } \\
\text { Reverse }\end{array}$ & $\begin{array}{l}\text { GTGGACTGGACATGCTCATTC } \\
\text { AGCAATCAGAGGTTGGGTCA }\end{array}$ & 212 \\
\hline Hsd11b2 & $\begin{array}{l}\text { Forward } \\
\text { Reverse }\end{array}$ & $\begin{array}{l}\text { CTGGCCACTGTGTTGGATTTG } \\
\text { TCCAGAACACGGCTGATATCCT }\end{array}$ & 122 \\
\hline Mfn1 & $\begin{array}{l}\text { Forward } \\
\text { Reverse }\end{array}$ & $\begin{array}{l}\text { GGAGATACAGGGCTACAGAAAC } \\
\text { AGCTCTTGCСАСTACTTGTC }\end{array}$ & 104 \\
\hline Opa1 & $\begin{array}{l}\text { Forward } \\
\text { Reverse }\end{array}$ & $\begin{array}{l}\text { GTGTCAACGCATGTGATCGA } \\
\text { GGATGACCCTCAAGCTGTCT }\end{array}$ & 295 \\
\hline Drp1 & $\begin{array}{l}\text { Forward } \\
\text { Reverse }\end{array}$ & $\begin{array}{l}\text { GTGAGCCCGTGGATGATAAA } \\
\text { AAATCCTAGCACCACCACATAG }\end{array}$ & 132 \\
\hline Tfam & $\begin{array}{l}\text { Forward } \\
\text { Reverse }\end{array}$ & $\begin{array}{l}\text { ACAAAGAAGCTGTGAGCAAGTA } \\
\text { GTGCTTTCTTCTTTAGGCGTTTC }\end{array}$ & 99 \\
\hline Pgc1a & $\begin{array}{l}\text { Forward } \\
\text { Reverse }\end{array}$ & $\begin{array}{l}\text { GTGGATGAAGACGGATTGCC } \\
\text { GGTGTGGTTTGCATGGTTCT }\end{array}$ & 219 \\
\hline$N r f 1$ & $\begin{array}{l}\text { Forward } \\
\text { Reverse }\end{array}$ & $\begin{array}{l}\text { GGAAACTCAGAGCCACATTAGA } \\
\text { GCGCCAAACACCTTAAAGAC }\end{array}$ & 109 \\
\hline Parkin & $\begin{array}{l}\text { Forward } \\
\text { Reverse }\end{array}$ & $\begin{array}{l}\text { CTCAGACAAGGACACATCAGTAG } \\
\text { TACATTGGAAGACCAAGACAGG }\end{array}$ & 110 \\
\hline Pink1 & $\begin{array}{l}\text { Forward } \\
\text { Reverse }\end{array}$ & $\begin{array}{l}\text { CAATGCCGCTGTGTATGAAG } \\
\text { GCTCCCTTTGAGACGACAT }\end{array}$ & 108 \\
\hline Rheb & $\begin{array}{l}\text { Forward } \\
\text { Reverse }\end{array}$ & $\begin{array}{l}\text { ACGATCCAACCATAGAAAACACA } \\
\text { TATTCATCCTGCCСTGCTGT }\end{array}$ & 97 \\
\hline Atp13a & $\begin{array}{l}\text { Forward } \\
\text { Reverse }\end{array}$ & $\begin{array}{l}\text { AGAGGGTCACTGCAAACAAC } \\
\text { GGTCCСTTCAATCCACACATAC }\end{array}$ & 98 \\
\hline Tnfa & $\begin{array}{l}\text { Forward } \\
\text { Reverse }\end{array}$ & $\begin{array}{l}\text { ACCACGCTCTTCTGTCTACT } \\
\text { ATGATCTGAGTGTGAGGGTCT }\end{array}$ & 115 \\
\hline Tnfaip3 & $\begin{array}{l}\text { Forward } \\
\text { Reverse }\end{array}$ & $\begin{array}{l}\text { GGAGACAGACACTCGGAATTT } \\
\text { CAAGTTGTCCCATTCGTCATTC }\end{array}$ & 121 \\
\hline$I l 1 b$ & $\begin{array}{l}\text { Forward } \\
\text { Reverse }\end{array}$ & $\begin{array}{l}\text { ACCTGTCCTGTGTGATGAAAG } \\
\text { CTCCACTTTGGTCTTGACTTCT }\end{array}$ & 131 \\
\hline Il6 & $\begin{array}{l}\text { Forward } \\
\text { Reverse }\end{array}$ & $\begin{array}{l}\text { GCCTTCTTGGGACTGATGTT } \\
\text { GGTCTGTTGTGGGTGGTATC }\end{array}$ & 95 \\
\hline Ccl2 & $\begin{array}{l}\text { Forward } \\
\text { Reverse }\end{array}$ & $\begin{array}{l}\text { GATGCAGTTAATGCCCCACT } \\
\text { TTCCTTATTGGGGTCAGCAC }\end{array}$ & 168 \\
\hline Ccl5 & $\begin{array}{l}\text { Forward } \\
\text { Reverse }\end{array}$ & $\begin{array}{l}\text { CCAACCTTGCAGTCGTCTTT } \\
\text { CTTGAACCCACTTCTTCTCTGG }\end{array}$ & 75 \\
\hline Csf2 & $\begin{array}{l}\text { Forward } \\
\text { Reverse }\end{array}$ & $\begin{array}{l}\text { ACAGTTTCTCAGCACCCACC } \\
\text { TCCAGAGCACGCATGTCATT }\end{array}$ & 109 \\
\hline Mmp2 & $\begin{array}{l}\text { Forward } \\
\text { Reverse }\end{array}$ & $\begin{array}{l}\text { GCTGATACTGACACTGGTACTG } \\
\text { GATCTGAGCAATGCCATCAAAG }\end{array}$ & 99 \\
\hline Mmp3 & $\begin{array}{l}\text { Forward } \\
\text { Reverse }\end{array}$ & $\begin{array}{l}\text { AGATGCTGGCATGGAGGTTC } \\
\text { AAGGTACTGAAGCCACCGAC }\end{array}$ & 114 \\
\hline Gapdh & $\begin{array}{l}\text { Forward } \\
\text { Reverse }\end{array}$ & $\begin{array}{l}\text { TCTCTGCTCCTCCCTGTTCTA } \\
\text { GGTAACCAGGCGTCCGATAC }\end{array}$ & 121 \\
\hline
\end{tabular}

Fkbp51(Fkbp5), FK506 binding protein 5; Hsd11b, 11ß-hydroxysteroid dehydrogenase; $M$ fn1, mitofusin 1; Opa1, optic atrophy 1, a dynamin-like GTPase; Drp1, dynamin related protein 1; Tfam, mitochondrial transcription factor A; Pgc1a, peroxisome proliferative activated receptor gamma coactivator 1 alpha; Nrf1, nuclear respiratory factor 1; Pink1, PTEN-induced putative kinase 1; Rheb, Ras homolog mTORC1 binding; Atp13a, ATPase cation transporting 13A2; Tnfa, tumor necrosis factor alpha; Tnfaip3, tumor necrosis factor alpha induced protein 3; 
$I l 1 b$, interleukin 1 beta; Ccl2, C-C motif chemokine ligand 2; Csf2, colony stimulating factor 2; Mmp2, matrix metallopeptidase 2; Gapdh, glyceraldehyde-3-phosphate dehydrogenase. 


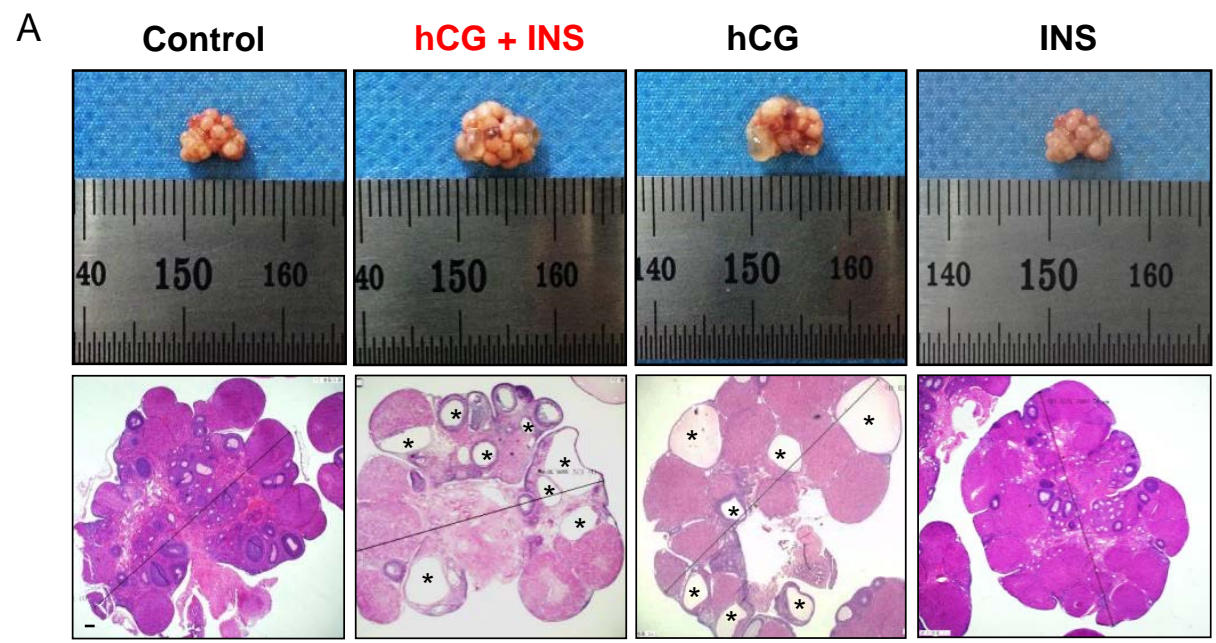

B

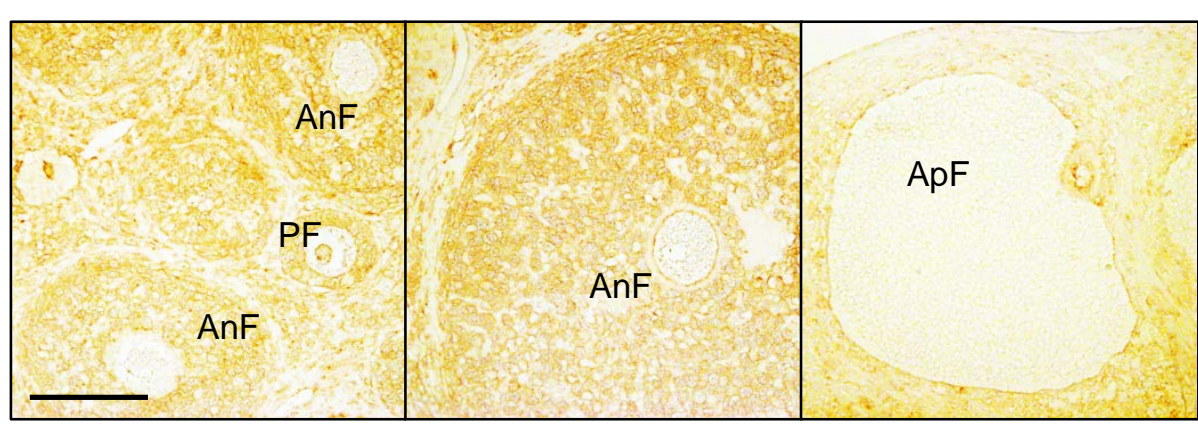

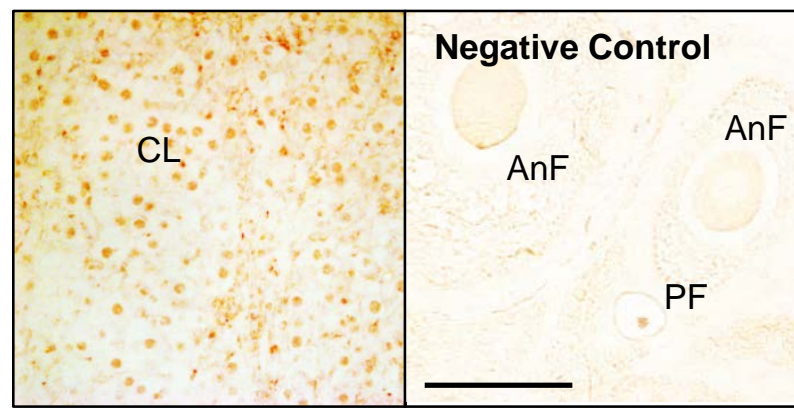

C

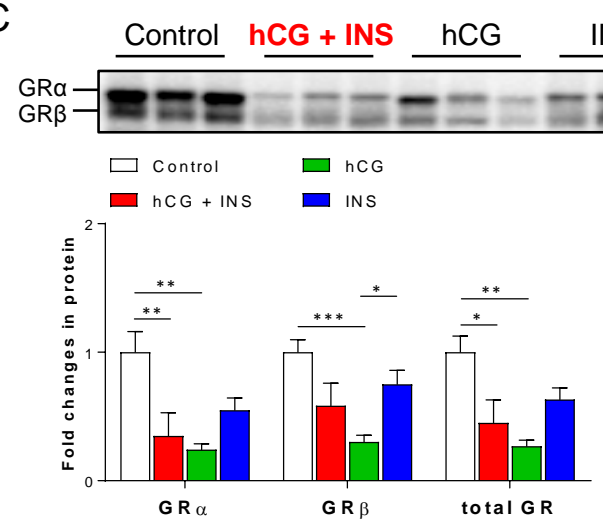

D

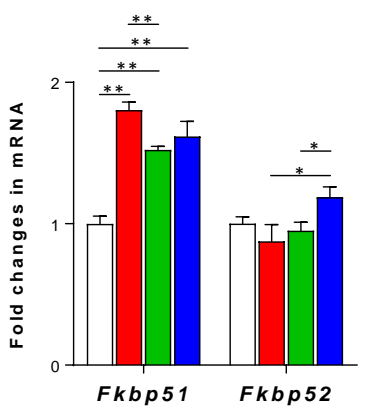

E

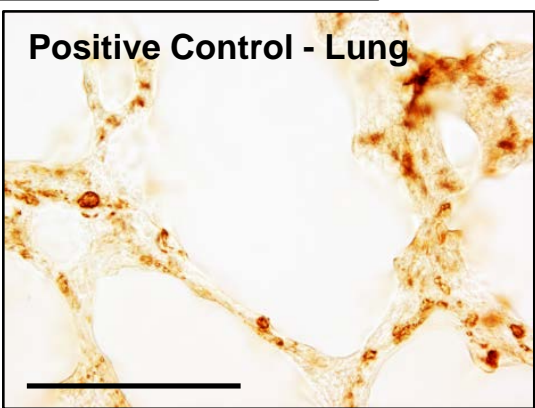




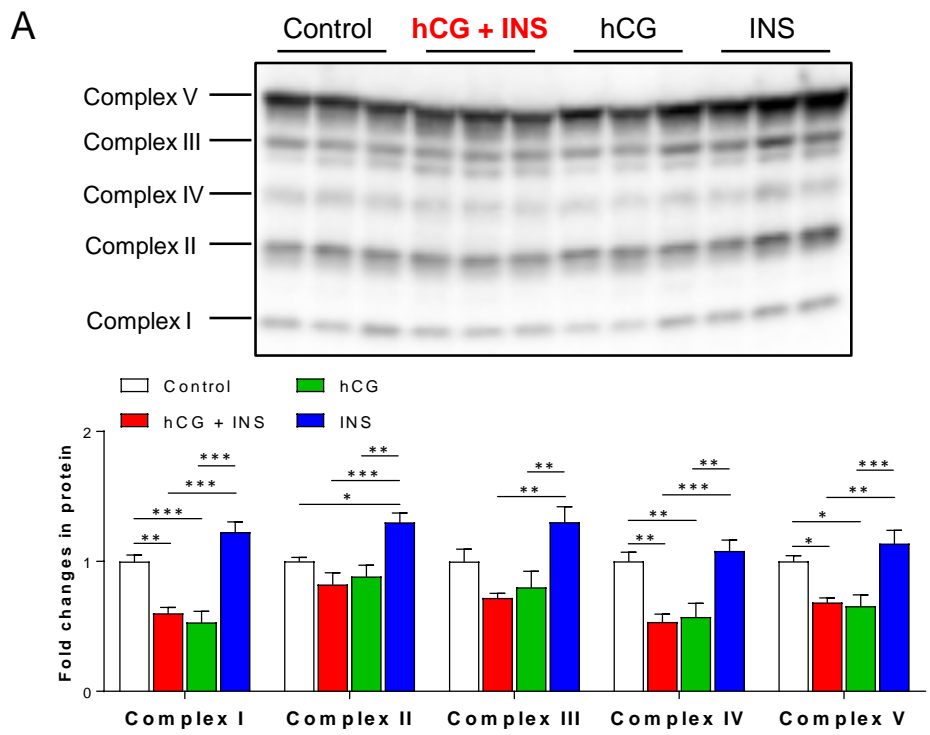

B
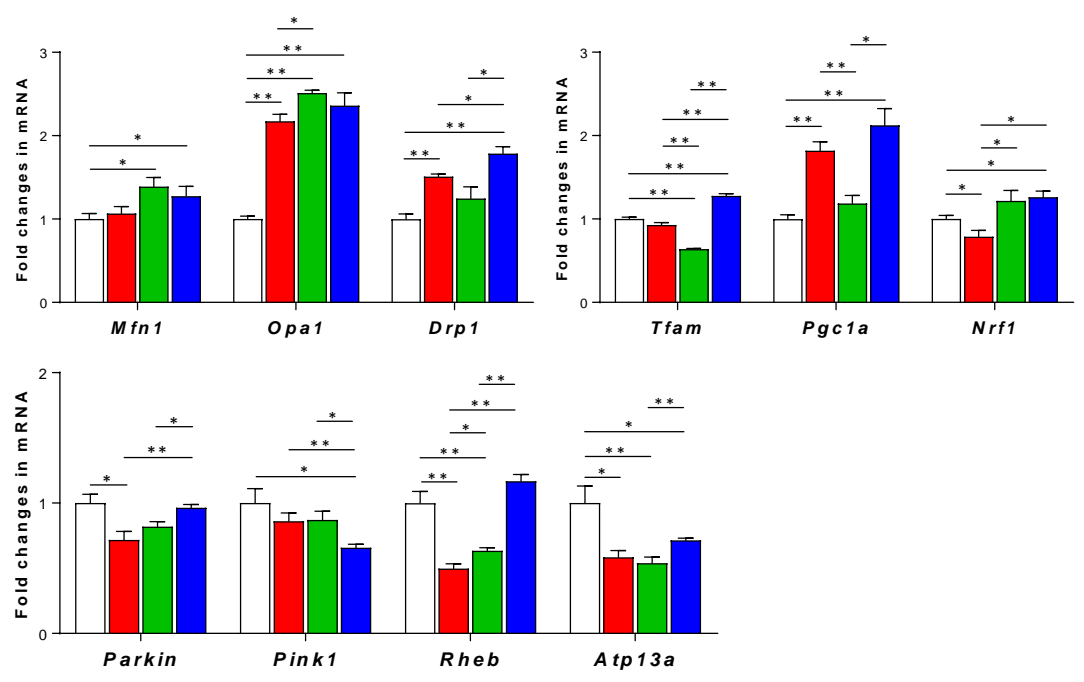
A
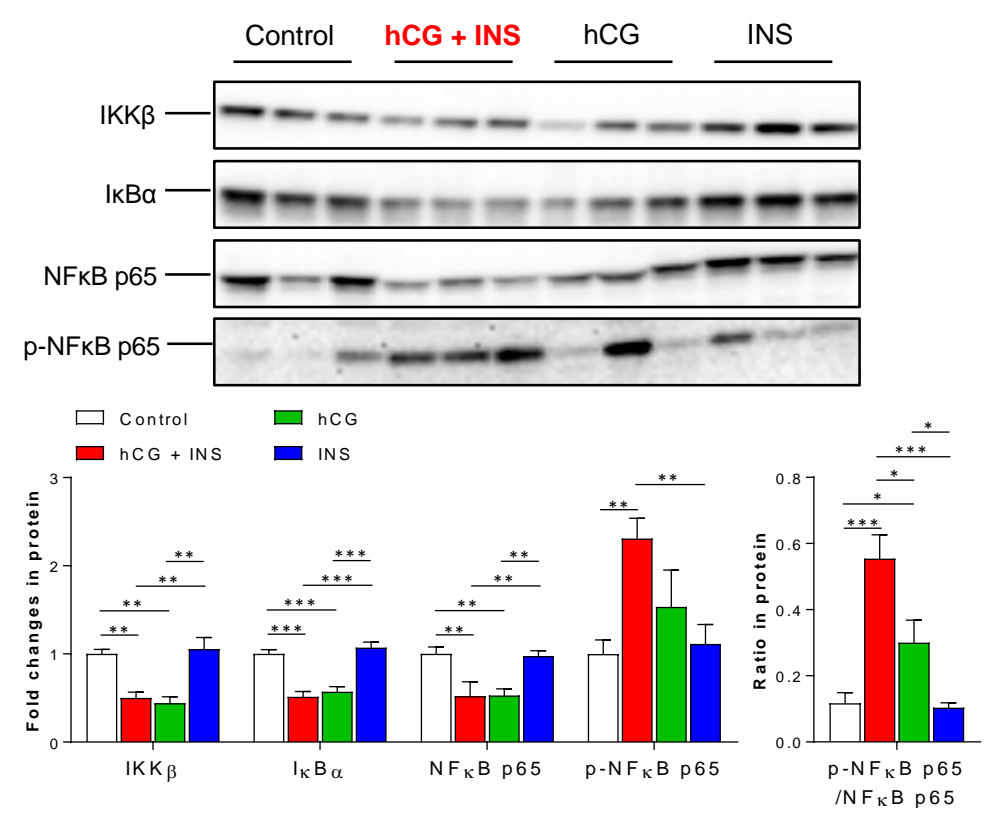

B

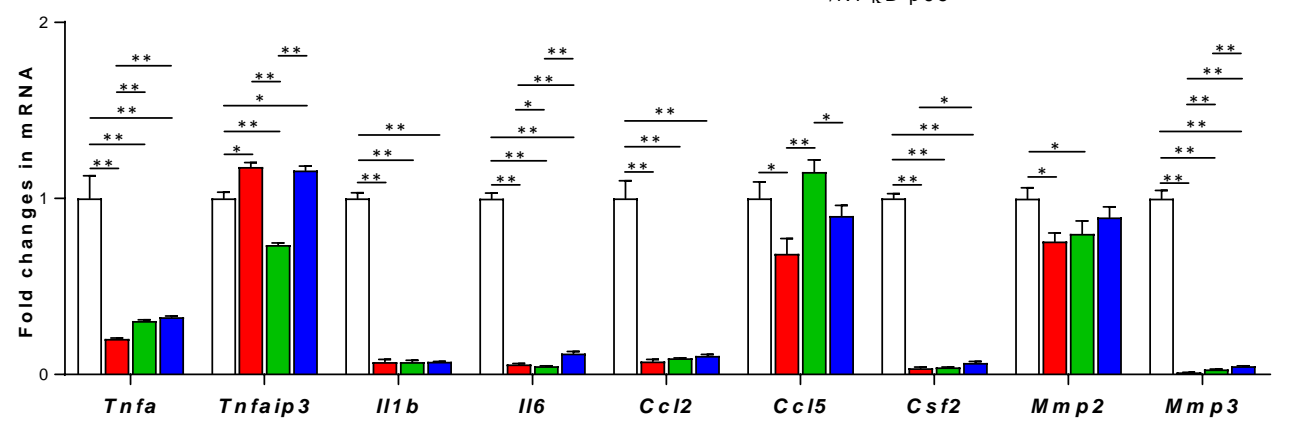

C
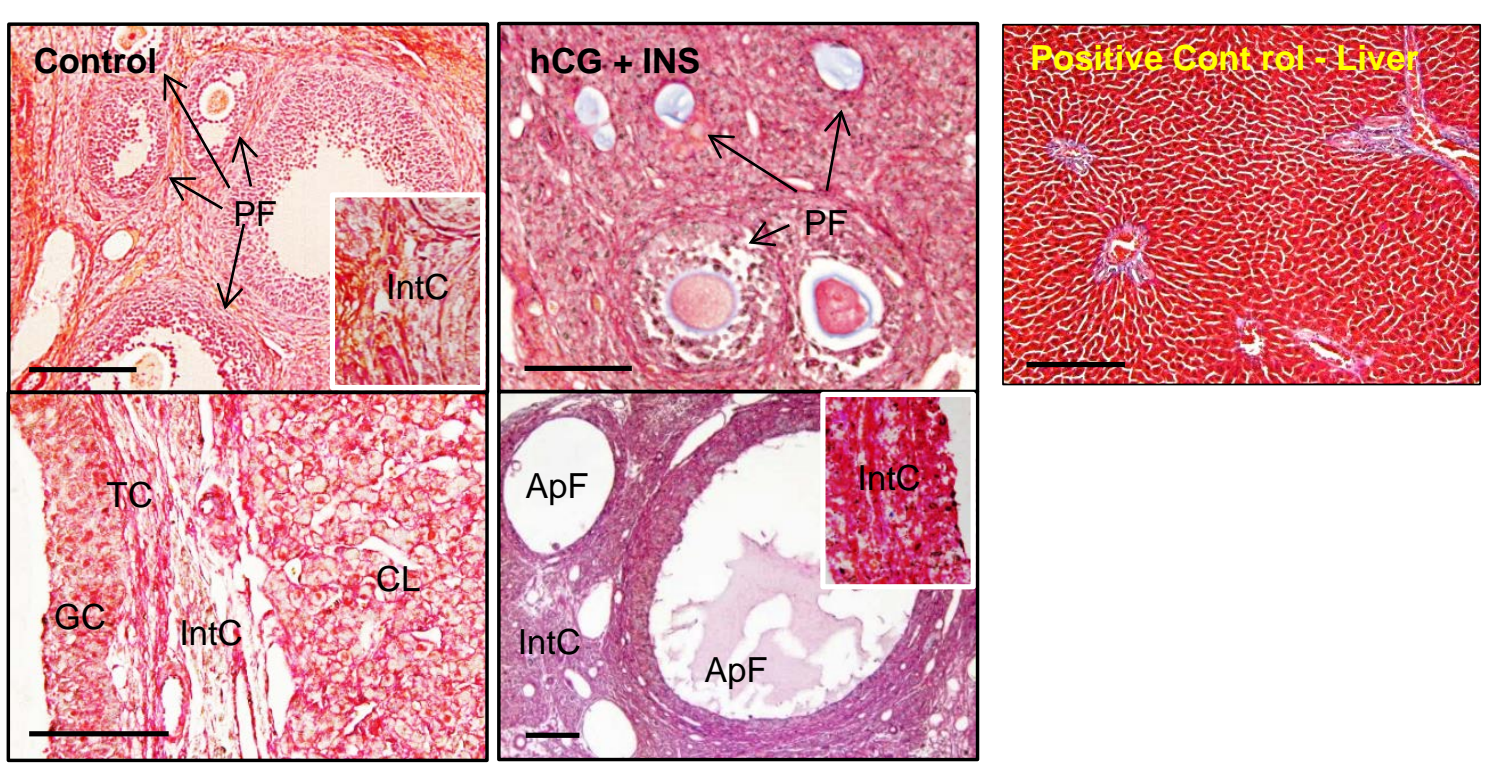

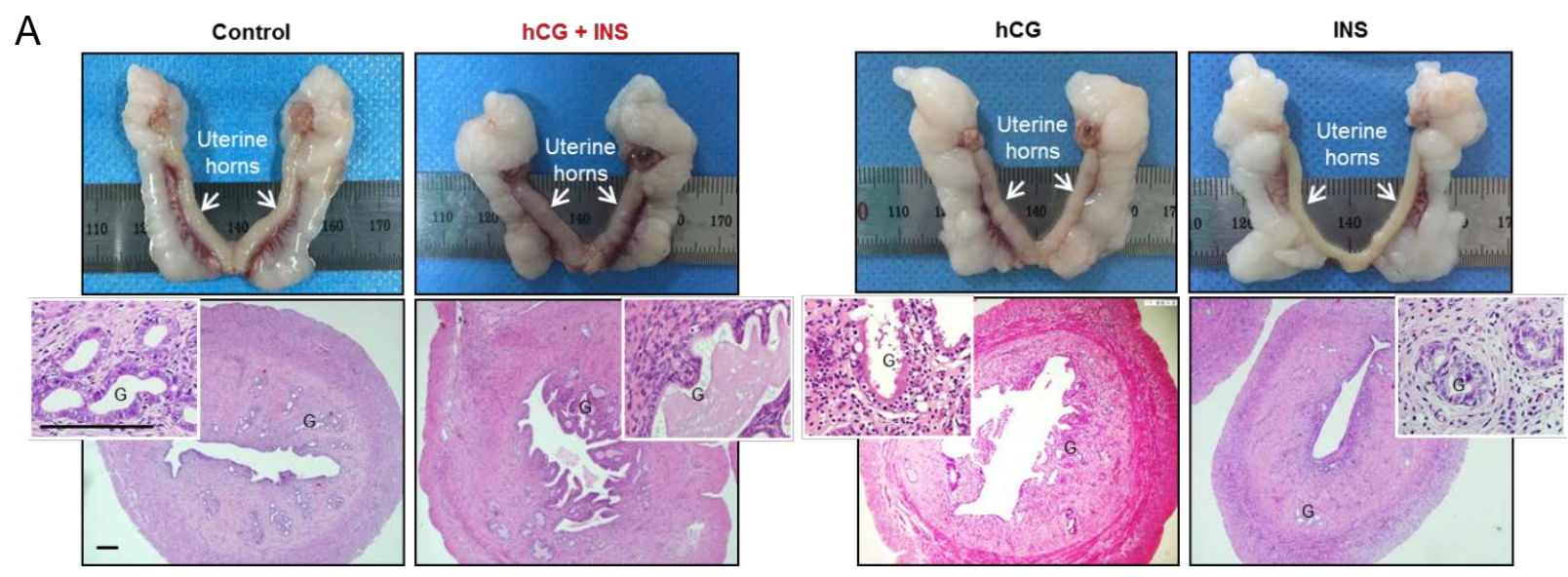

B
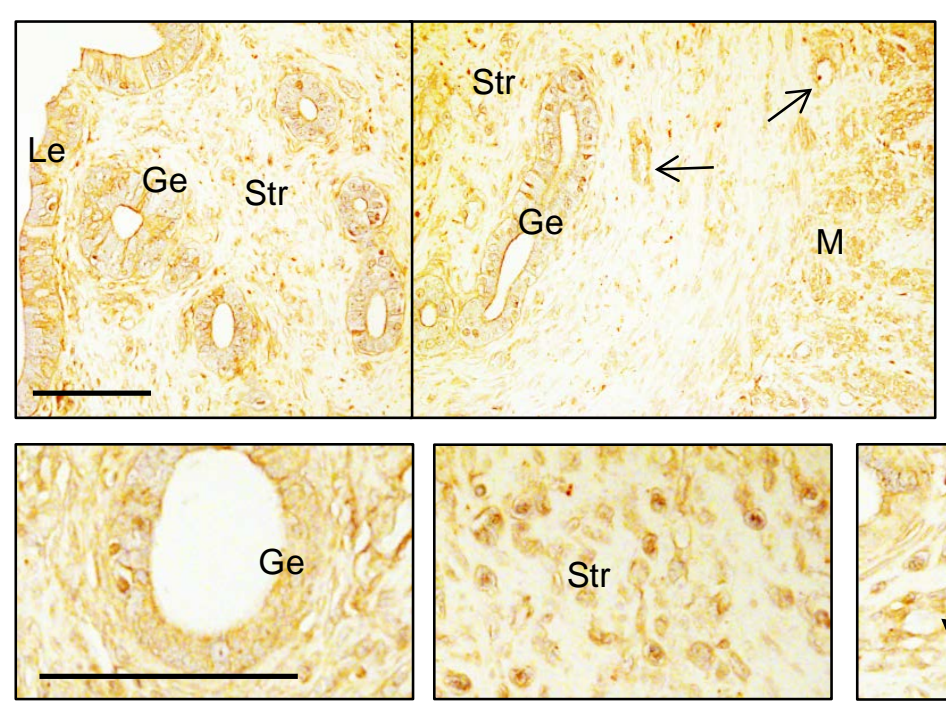

C
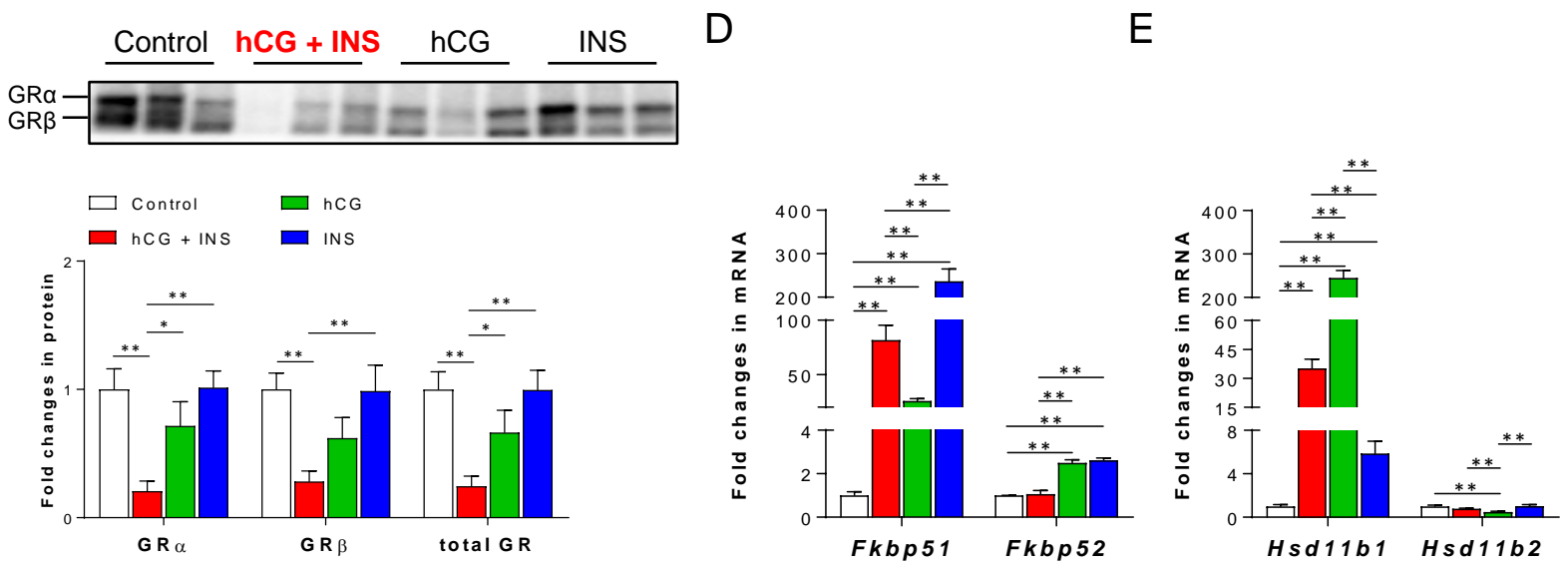
A
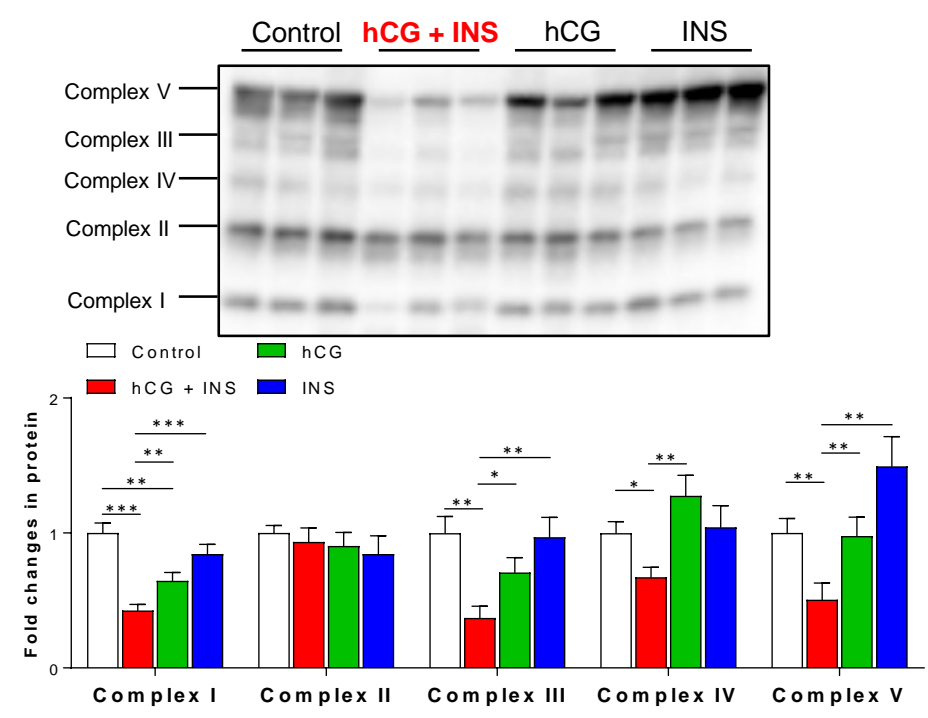

B
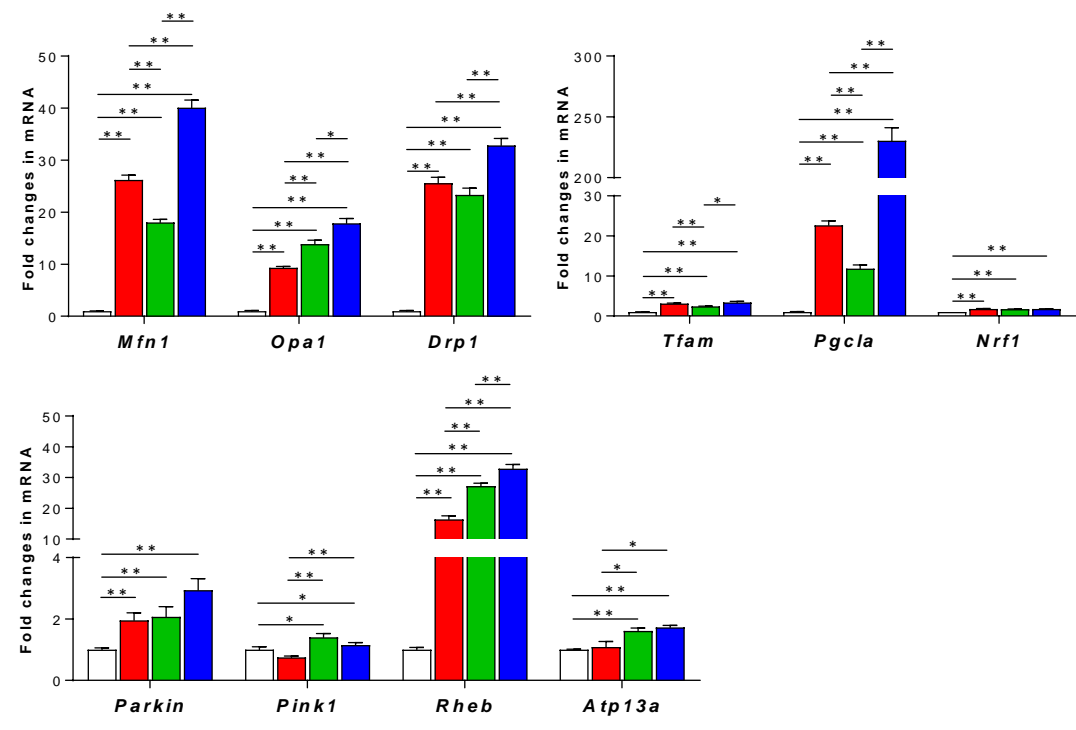
A
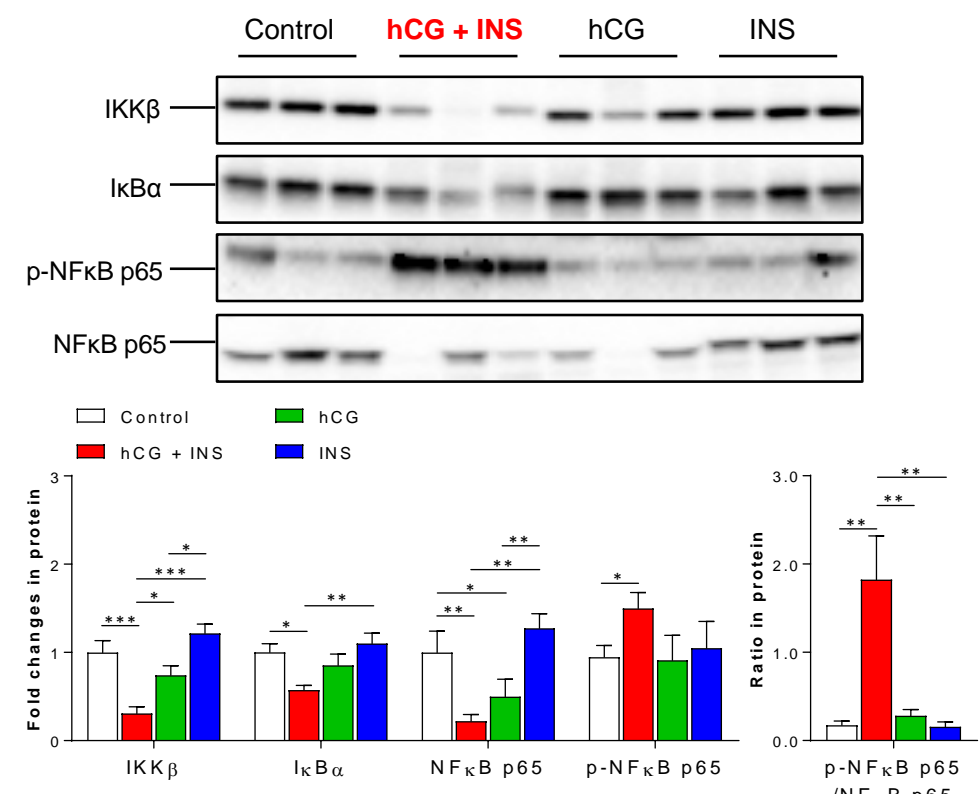

B

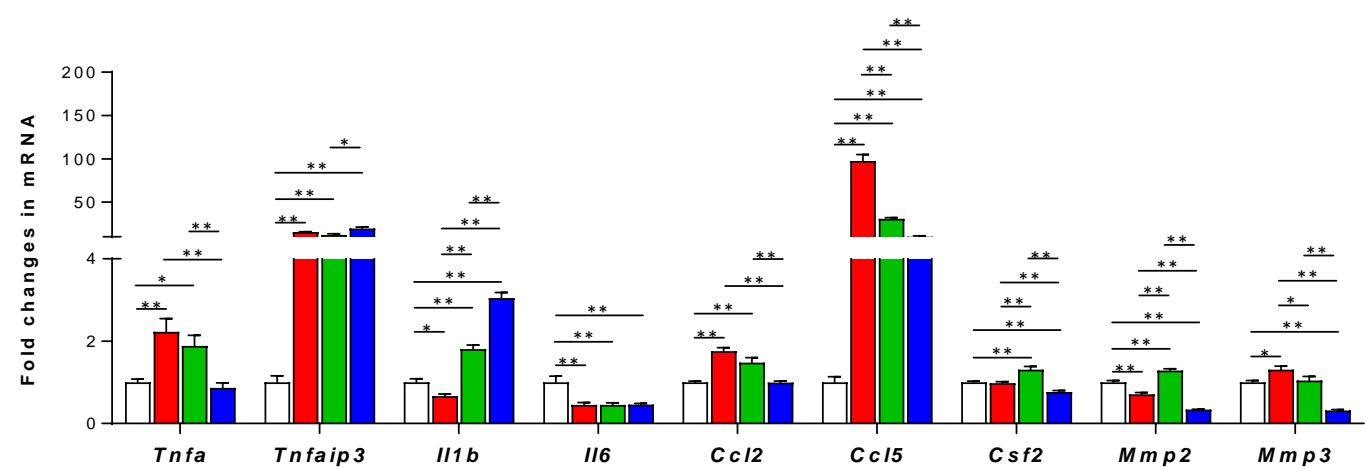

C

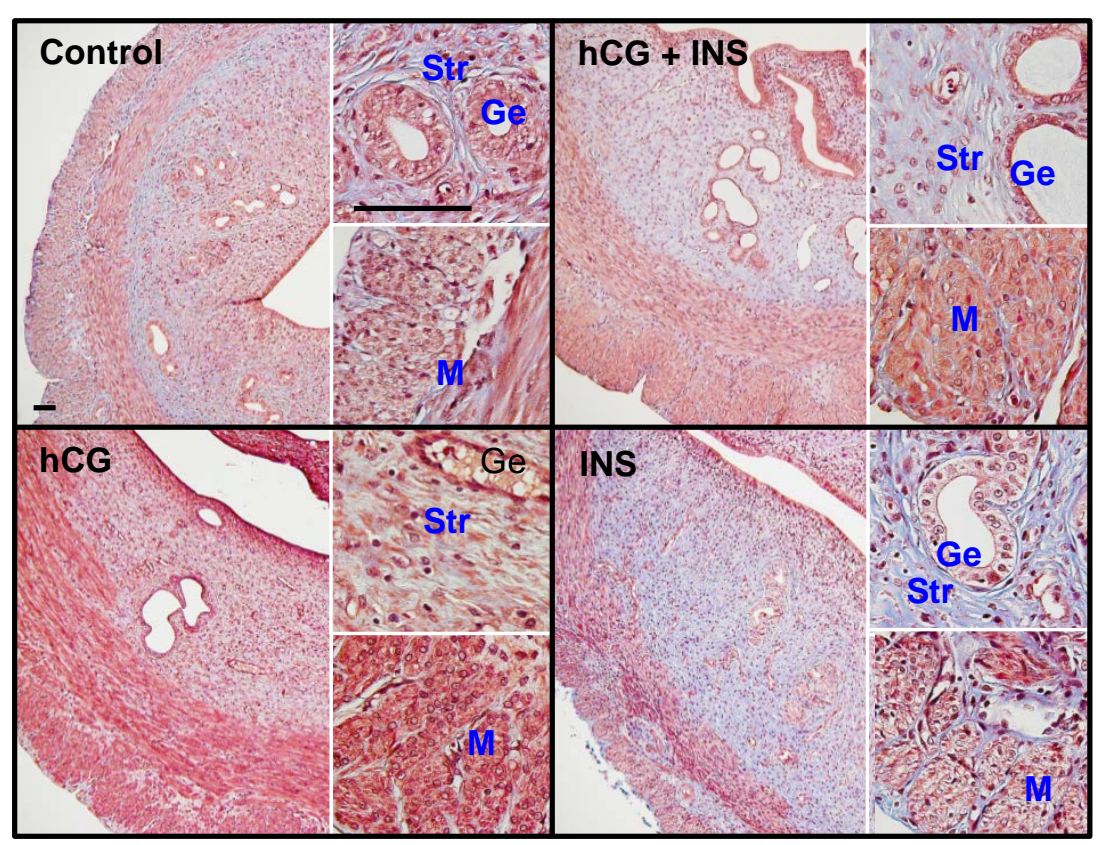

